Review

\title{
The Periconceptional Environment and Cardiovascular Disease: Does In Vitro Embryo Culture and Transfer Influence Cardiovascular Development and Health?
}

\author{
Monalisa Padhee, Song Zhang, Shervi Lie, Kimberley C. Wang, Kimberley J. Botting, \\ I. Caroline McMillen, Severence M. MacLaughlin and Janna L. Morrison *
}

Early Origins of Adult Health Research Group, School of Pharmacy and Medical Sciences, Sansom Institute for Health Research, University of South Australia, Adelaide, SA 5001, Australia; E-Mails: padmy002@mymail.unisa.edu.au (M.P.); song.zhang@unisa.edu.au (S.Z.); shervi.lie@mymail.unisa.edu.au (S.L.); kimberley.wang@mymail.unisa.edu.au (K.C.W.); kb555@cam.ac.uk (K.J.B.); caroline.mcmillen@newcastle.edu.au (I.C.M.); severence.maclaughlin@gmail.com (S.M.M.)

* Author to whom correspondence should be addressed; E-Mail: janna.morrison@unisa.edu.au; Tel.: +61-8-8302-2166; Fax: +61-8-8302-2389.

Received: 21 November 2014 / Accepted: 30 January 2015 / Published: 18 February 2015

\begin{abstract}
Assisted Reproductive Technologies (ARTs) have revolutionised reproductive medicine; however, reports assessing the effects of ARTs have raised concerns about the immediate and long-term health outcomes of the children conceived through ARTs. ARTs include manipulations during the periconceptional period, which coincides with an environmentally sensitive period of gamete/embryo development and as such may alter cardiovascular development and health of the offspring in postnatal life. In order to identify the association between ARTs and cardiovascular health outcomes, it is important to understand the events that occur during the periconceptional period and how they are affected by procedures involved in ARTs. This review will highlight the emerging evidence implicating adverse cardiovascular outcomes before and after birth in offspring conceived through ARTs in both human and animal studies. In addition, it will identify the potential underlying causes and molecular mechanisms responsible for the congenital and adult cardiovascular dysfunctions in offspring whom were conceived through ARTs.
\end{abstract}

Keywords: assisted reproductive technology; in vitro fertilization; periconceptional period; cardiovascular disease; epigenetics 


\section{Introduction}

In recent years, the use of Assisted Reproductive Technologies (ARTs) have increased rapidly as a result of increasing infertility rates in humans and increasing demand for the reproduction of livestock with desired genetic characteristics. There are, however, a range of controversial issues surrounding in vitro embryo culture and embryo transfer, both of which are important processes in ARTs. These processes occur during the periconceptional period and are known to involve manipulation of the nutritional environment. Hence, to understand the link between ARTs and their effects on cardiovascular health, we need to understand and address these major questions:

(1) When is the periconceptional period?

(2) Why is the periconceptional period a critical window of embryonic development?

(3) What are the different procedures involved in ARTs and how do these impact the periconceptional environment?

(4) What is the evidence that the periconceptional environment influences cardiovascular health in fetal life and in adulthood?

(5) What is the evidence that ARTs influence cardiovascular health before and after birth?

(6) What are the most likely mechanisms linking ARTs and risk of cardiovascular disease in fetal and adult life?

\section{When Is the Periconceptional Period?}

ARTs involve manipulations that occur during oocyte maturation, fertilization and preimplantation, each of which is part of the periconceptional period and are likely to involve changes in the nutritional environment during this period [1,2]. The term "periconceptional" is defined as the period before and immediately after the time of conception and is a critical period during early development [3]. Most human studies have included different time frames in defining the periconceptional period and these depend on the specific research questions (Figure 1). For example, a study of maternal multivitamin supplementation in the periconceptional period on congenital abnormalities, included from one month prior to conception to about two months after conception [4]. Another study investigating the effect of periconceptional maternal characteristics on embryonic development has defined 14 weeks prior to conception as the periconceptional period [5].

Similar to human studies, animal studies have used different timings around conception to define the periconceptional period (Figure 1). For example, the periconceptional period is defined as 3-6 days before and 1 day after conception in one study and 3.5 days before and after conception in another study in mice (term, 19 days) [6,7]. In rats (term, 21 days), the periconceptional period is defined as 3 weeks prior to and 5 days after conception, whereas in another study, it is defined as 4.25 days after conception $[8,9]$. In sheep (term, 145-150 days), different definitions of the periconceptional period have been used to investigate the impact of maternal nutrition in the periconceptional period on the development and health of the offspring (Figure 1). The Auckland model defines the periconceptional period as extending from 60 days prior to conception until 30 days gestation (term, 145 days) [10,11]. This period includes oocyte maturation, preimplantation and postimplantation of the embryo as well as early placentation [12], because implantation occurs on day 16 of gestation in sheep [12]. The Nottingham model includes the 
period between day 0 till day 30 of gestation (term, 147 days), which covers embryo/blastocyst development, preimplantation development of the embryo and the period of implantation [13]. A commonality between these models is that the period of intervention extends beyond the periconceptional period to the postimplantation period and thus includes processes such as development of the uterine glands which provide nutrition (uterine histotroph) to the developing embryo and the process of placentation [14] Thus extension into the postimplantation period may not provide evidence of changes that are specific to manipulations during oocyte maturation and embryo development [15]. In contrast, the Adelaide model is restricted to the critical windows of oocyte maturation and preimplantation embryo development (60 days prior conception to 7 days after conception; term, 150 days) [16]. Similarly, the Southampton model also includes 15 days before until 15 days after conception (term, 147 days), which includes oocyte maturation and blastocyst formation [17]. Therefore, isolating the impact of perturbations during oocyte maturation and the preimplantation period alone from those of the postimplantation and placentation periods [18-20].

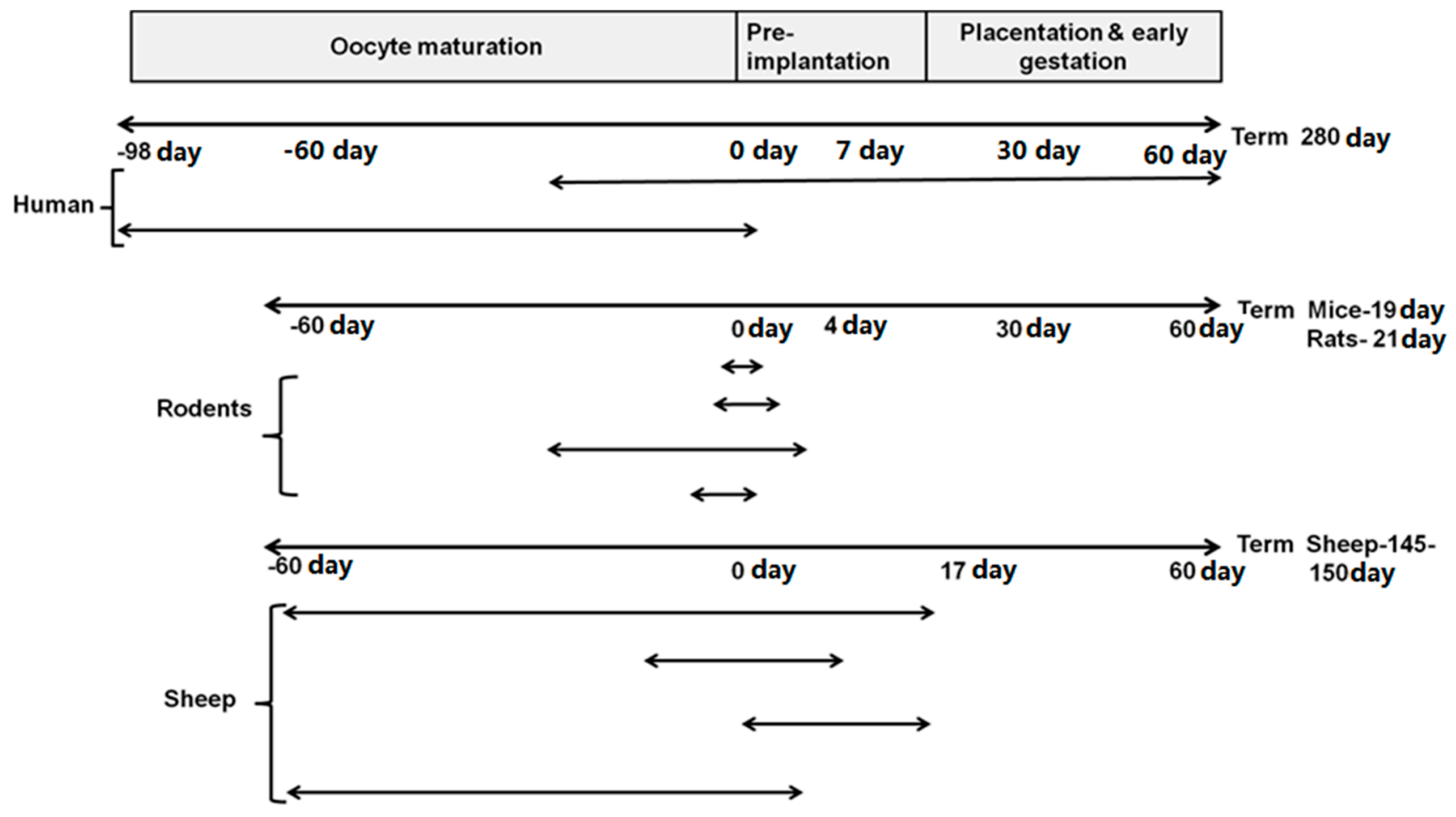

Figure 1. Different models of the periconceptional period in studies in humans, rodents and ruminants include different stages of oocyte and embryo development. Note: Implantation occurs at different days after conception across species (Human, 7-9 days; Rodents, 6-7 days; Sheep 16 days) [4-10,13,16,17]. 


\section{Why Is Periconceptional Period a Critical Window of Development?}

\subsection{Oogenesis Occurs Early in Life}

A women's reproductive function is determined in fetal life because the specialized cells known as primordial germ cells (PGCs), that give rise to gametes, are present within the wall of the yolk sac at 4-6 weeks gestation [21-23]. PGCs migrate from the yolk sac to the genital ridge between 6 and 12 weeks gestation and differentiate into oogonia after becoming invested by somatic support cells [21]. By 12 weeks gestation, oogonia commence the first meiotic prophase and are called primary oocytes. Immediately after this, they become dormant in the early diplotene stage [23]. When the nuclei of these primary oocytes enlarge and become watery, the primary oocytes are known as germinal vesicles. The primary oocyte, surrounded by a single layered, squamous capsule of epithelial follicles is the primordial follicle [24]. At $\sim 5$ months gestation, the pool of these follicles reaches its peak of $\sim 7$ million, however, most of these follicles degenerate and the maximum number of oocytes a female will have in her lifetime is set at birth, ranging from 700,000 to 2 million [25,26], with only 400,000 follicles remaining at puberty $[23,25]$. Any changes in the maternal nutritional environment such as under- or overnutrition can affect oogenesis and other reproductive functions and hence can have an impact on the granddaughter's reproductive health [27-30]. Studies have also shown that nutritional manipulations during pregnancy can have transgenerational effects, since they not only alter cardiovascular outcomes in the offspring but can also result in cardiovascular dysfunction and alter glucose and insulin control in the next generation [31-34]. Thus, in addition to understanding the impact of ARTs on the cardiovascular health of the offspring, it will be of interest to understand the impact on the grandchildren.

During and after puberty, hormonal secretions from the hypothalamus, anterior pituitary gland and ovary regulate the menstrual cycle, which averages 28 days in humans, 17 days in sheep and 4-5 days in rodents [35-38]. A small group of primordial follicles are converted into primary follicles with a decrease in inhibitory signals and/or an increase in stimulatory factors which remain largely unknown [39-41]. The granulosa cells undergo a squamous to cuboidal epithelial morphology from primordial to primary, and then several layers of granulosa cells begin to develop to form secondary follicle and the theca cells emerge in the transition from primary to secondary follicle [23,40]. A thick glycoprotein layer surrounds the surface of the oocyte known as zona pellucida [42]. Some of these follicles degenerate, but a few enlarge in response to rising levels of follicle stimulating hormone (FSH) and develop a fluid filled cavity known as the antrum from fluid generated by granulosa cell secretions and by plasma transudate (antral follicle) $[43,44]$. Eventually, one of the antral follicles becomes dominant (mature Graafian follicle), while the others degenerate [41]. At $~ 13-14$ days of the menstrual cycle in humans, the primary oocyte resumes meiosis under the influence of the ovulatory surge of luteinizing hormone ( $\mathrm{LH}$ ) caused by positive feedback of estrogen, produced by the dominant follicle, on the pituitary gland and hypothalamus [23]. At the end of the first meiotic division, a small polar body containing a set of chromosomes is released into the perivitelline space [24]. Then the oocyte progresses to the second meiotic division, where it is again arrested in metaphase $\sim 3 \mathrm{~h}$ before ovulation. Follicular rupture and ovulation occurs $\sim 38 \mathrm{~h}$ after the beginning of the ovulatory surge [23]. The oocyte then moves into the ampulla of the oviduct and remains viable for fertilization for $24 \mathrm{~h}$. Fusion of the sperm enables the oocyte to resume meiosis [45]. At the end of the second meiosis, the oocyte divides into two 
unequal cells: a polar body and the female pronucleus. The sperm loses its nuclear envelope, undergoes chromatin decondensation and replacement of the sperm specific protamine by histones. The DNA from the sperm binds to the histones in the oocyte and is surrounded by a new nuclear envelope of maternal origin, which forms the male pronucleus. The fusion of the pronuclei of sperm and oocyte results in a zygote [46]. Perturbations during oocyte maturation, such as those that may occur during parts of ART (ovarian hyperstimulation, in vitro maturation and in vitro fertilization (IVF)) have been shown to reduce the quality of oocytes and embryo viability as well as alter energy metabolism of the oocytes $[47,48]$. This has been shown to result in delayed embryonic development, increased abnormal blastocyst formation, fetal growth retardation, increased fetal loss, congenital malformations, imprinting disorders, and a range of postnatal growth and development disorders such as poor cognitive development, increased risk for neurological problems, cardiovascular diseases and respiratory tract infections [47,49-54]. In addition, superovulation can also perturb proper placental and fetal development by altering trophoblast differentiation and distribution of cell types in the placenta [55].

\subsection{Key Events in Embryonic Development during the Periconceptional Period in Different Species}

Studies in humans and animals have shown that nutritional manipulations during blastocyst formation, such as culturing the embryo in media, have been associated with cleavage anomalies, improper embryo development, an altered placental transcriptome, fetal and birth defects, increased blood pressure, vascular dysfunctions, poor neuromotor development, behavioural disorders and imprinting disorders [56-63]. In addition, the maturation of endometrium in human also takes place before implantation and studies have shown that ovarian stimulation could alter endometrial receptivity and impair implantation rate $[64,65]$. There is variation between species in the timing of ovulation after the beginning of estrous, completion of the second cleavage, hatching from the zona pellucida and implantation [66]. The steps from fertilization to implantation of the embryo include several major processes such as decondensation of parental genomes and cleavage to blastomere formation which includes an equal first cleavage ( 2 cell), and subsequent asynchronous division resulting in 4, 8, 16, 32 cell stages; (Table 1) [23,46]. With the development of a fluid filled cavity by the process of compaction, a blastocyst is formed [23]. The inner cell mass of the blastocyst will give rise to the embryo, the yolk sac, amnion and allantois while the outer cell mass develops into the chorion. As the hydrostatic pressure of the fluid increases within the cavity of the blastocyst, it expands and the zona pellucida is digested by enzymes which allow hatching of the embryo. This is followed by implantation of the embryo in the uterine wall (Table 1).

\subsubsection{Humans}

Ovulation occurs in the middle of the menstrual cycle i.e., around the 14th day of the cycle [67]. After fertilization, the formation of 2 cell (first cleavage), 4 cell, 8 cell and 16 cell (morula) stages take place at $24,40,50,72 \mathrm{~h}$, respectively. By the 5 th day, the blastocyst is formed, followed by zona hatching at 5-7 days and implantation at 7-9 days (Table 1). 
Table 1. Timing of important events in the periconceptional period in relation to ovulation $[66,68,69]$.

\begin{tabular}{ccccc}
\hline $\begin{array}{l}\text { Timing of events during the } \\
\text { periconceptional period }\end{array}$ & Human & Mouse & Rat & Sheep \\
\hline Time between ovulations & 28 days & $4-5$ days & $4-5$ days & 17 days \\
Time to 2 cell stage (first cleavage) & $24 \mathrm{~h}$ & $21-23$ & $20.6 \mathrm{~h}$ & $24-26 \mathrm{~h}$ \\
Time to 4 cell stage & $40 \mathrm{~h}$ & $38-50$ & $72 \mathrm{~h}$ & $30-36 \mathrm{~h}$ \\
Time to 8 cell stage & $50 \mathrm{~h}$ & $50-60$ & $78 \mathrm{~h}$ & $42-45 \mathrm{~h}$ \\
Time to 16-32 cells (morula stage) & $72 \mathrm{~h}$ & $60-70$ & $84 \mathrm{~h}$ & $63-86 \mathrm{~h}$ \\
Formation of blastocyst & 5 days & $3-4$ days & $4-5$ days & $5-6$ days \\
Zona hatching & $5-7$ days & 3.5 & 6 days & 8 days \\
Implantation & $7-9$ days & $4-5$ days & $6-7$ days & 16 days \\
Zygotic gene activation & $40-50 \mathrm{~h}$ & $24 \mathrm{~h}$ & $24 \mathrm{~h}$ & $30-45 \mathrm{~h}$ \\
\hline
\end{tabular}

\subsubsection{Rats}

Ovulation in rats and mice occurs after the first two stages (proestrus and estrus) of estrous cycle, which is $\sim 10 \mathrm{~h}$ after the start of estrus [70,71]. The embryo divides to form the 4 cell stage (second cleavage) by $38-50 \mathrm{~h}$ in mice and $72 \mathrm{~h}$ in rats, which is at a later time point than in humans. The blastocyst is formed at around 3-4 days in mice and 4-5 days in rats followed by hatching at day 3-3.5 in mice and at day 6 in rats. Implantation occurs at days 4-5 in mice and 6-7 in rats [72,73] (Table 1).

\subsubsection{Sheep}

Ovulation occurs 20-30 h after the beginning of estrus [35]. After the fertilization, the first cleavage division occurs $24 \mathrm{~h}$ after ovulation (Table 2), followed by the 4,8 and 16 cell stages at 30-36 h, $42-45 \mathrm{~h}$ and $63-86 \mathrm{~h}$, respectively. The formation of the blastocyst occurs between 5 and 6 days after ovulation in sheep $[12,74]$. Hatching takes place at day 8 , so that elongation can occur prior to implantation at day $16[12]$.

\subsection{Zygotic Gene Activation Occurs during Early Embryogenesis}

One of the major events after fertilization is the transition of control of the developmental program of the zygote/embryo from maternally derived transcripts and proteins accumulated in the oocyte during the process of oogenesis to embryonic transcripts and proteins [75]. This transition is known as zygotic gene activation or embryonic gene activation [76]. Zygotic gene activation is associated with three main functions: (i) to degrade maternally inherited transcripts; (ii) to replace the oocyte specific transcripts that are common to both the oocyte and early embryo with zygotic transcripts; and (iii) to promote the generation of novel embryo specific transcripts by reprogramming the pattern of gene expression [68]. In humans and sheep the maternal-zygotic transition occurs between 4-8 cell stage and 8-16 cell stage respectively and is associated with the developmental loss of totipotency and in mice and rats, this occurs by the 2 cell stage (Table 1) [77]. The initiation of zygotic transcription also coincides with demethylation during embryogenesis, which is an important event in epigenetic programming that can affect chromatin structure and gene expression [78]. Nutritional manipulations such as culturing embryos in various 
media have been shown to delay the transcription of important growth factors such as platelet-activating factor-receptor in mouse preimplantation embryos, which can affect the viability of the embryo [79]. Studies have shown that IVF has differential effects on growth factors by either delaying the first onset of expression of some of growth factors after the activation of zygotic genome or by decreasing the expression, which can hamper proper embryogenesis in mice [80].

Table 2. Assisted Reproductive Technologies (ARTs) and manipulations during oocyte/embryo development $[81,82]$.

\begin{tabular}{|c|c|c|}
\hline $\begin{array}{l}\text { ART } \\
\text { Treatment }\end{array}$ & Infertility Treated & Procedures Involved and Manipulation of Oocyte/Embryo Development \\
\hline IVF & $\begin{array}{l}\text { Blocked Fallopian tubes, } \\
\text { endometriosis, } \\
\text { unexplained infertility, } \\
\text { ovarian failure, } \\
\text { ovulatory disorders and } \\
\text { male infertility }\end{array}$ & $\begin{array}{c}\text { Controlled ovarian hyperstimulation - Oocyte and follicular development } \\
\text { Oocyte retrieval and transfer-Oocyte and follicular development } \\
\text { Sperm retrieval and preparation-No direct effect on embryo } \\
\text { In vitro fertilization - zygote } \\
\text { In vitro embryo culture - zygote, cleavage, morula, blastocyst } \\
\text { Embryo transfer-blastocyst }\end{array}$ \\
\hline GIFT & $\begin{array}{l}\text { Sperm dysfunction, } \\
\text { endometriosis or } \\
\text { unknown fertility }\end{array}$ & $\begin{array}{l}\text { Controlled ovarian hyperstimulation - Oocyte and follicular development } \\
\text { Oocyte retrieval - Oocyte and follicular development } \\
\text { Sperm retrieval and preparation - No direct effect on embryo }\end{array}$ \\
\hline ZIFT & $\begin{array}{l}\text { Severe male infertility, } \\
\text { immunologic infertility or } \\
\text { unexplained infertility }\end{array}$ & $\begin{array}{l}\text { Controlled ovarian hyperstimulation - Oocyte and follicular development } \\
\text { Oocyte retrieval - Oocyte and follicular development } \\
\text { Sperm retrieval and preparation - No direct effect on embryo } \\
\text { In vitro fertilization - zygote } \\
\text { In vitro embryo culture-zygote, cleavage }\end{array}$ \\
\hline AI and IUI & Male infertility & No direct effect on oocyte development \\
\hline ICSI & Male infertility & $\begin{array}{c}\text { Controlled ovarian hyperstimulation - Oocyte and follicular development } \\
\text { Oocyte retrieval-Oocyte and follicular development } \\
\text { Sperm retrieval and preparation-No direct effect on embryo } \\
\text { In vitro fertilization-Zygote } \\
\text { In vitro embryo culture-Zygote, cleavage, morula, blastocyst } \\
\text { Embryo transfer-Blastocyst }\end{array}$ \\
\hline
\end{tabular}

AI, artificial insemination; GIFT, gamete intraFallopian transfer; ICSI, intracytoplasmic sperm injection; IVF, in vitro fertilization; IUI, intrauterine insemination. ZIFT, zygote intraFallopian transfer.

\subsection{Epigenetics Reprogramming Is an Important Event in Both Gametogenesis and Embryogenesis}

Epigenetics is defined as all meiotically and mitotically heritable changes in gene expression that occur without changes in the DNA sequence [83,84]. One of the main mechanisms involved is DNA methylation (other mechanisms involved are histone modifications such as acetylation, phosphorylation, methylation, ubiquitination and sumoylation) [85,86]. During mammalian development, gametogenesis and embryogenesis are the two critical periods where epigenetic reprogramming occurs (Figure 2) [87]. This begins with demethylation when PGCs migrate along the genital ridge followed by sex-specific pattern of remethylation before fertilization $[88,89]$. There is a second wave of whole genomic demethylation in the male pronucleus within hours of fertilization whereas the female pronucleus undergoes complete demethylation after several cleavage divisions [90]. During implantation, genome-wide methylation 
takes place in a lineage-specific pattern [89]. However, there are certain genes, known as imprinted genes, that undergo erasure of methylation marks during PGC development and the methylation marks are re-established during gametogenesis but escape the second wave of demethylation that occurs after fertilization and thus maintain their methylation of $\mathrm{CpG}$ islands that was established during gametogenesis [91,92]. Imprinted genes are expressed differentially depending on their inheritance from maternal or paternal origin [93]. During development, one of the alleles of a particular gene is expressed only in the zygote and the other allele is silenced, and this process is known as genomic imprinting [87].

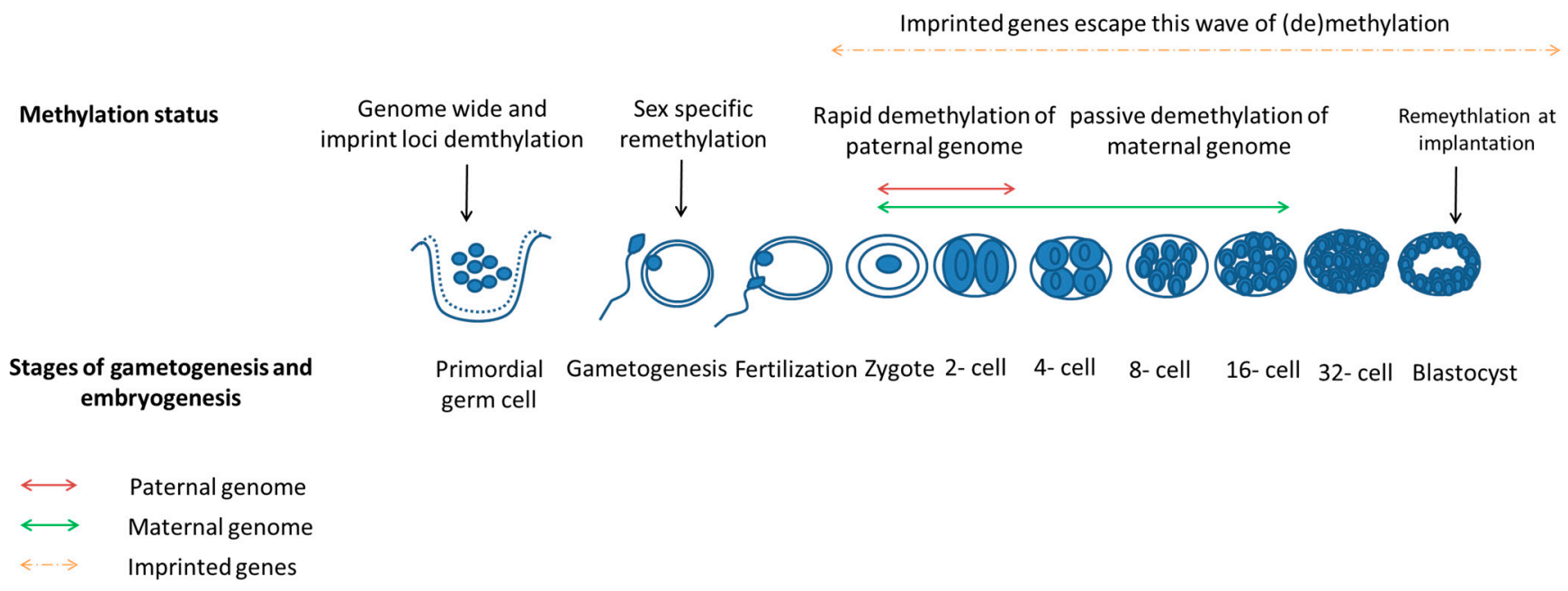

Figure 2. Epigenetic reprogramming during gametogenesis and embryogenesis. Adapted from $[87,94]$.

This epigenetic reprogramming is essential for proper development because it controls expression of early embryonic genes, cell cleavage and cell determination [95]. Imprinted genes, in particular, play an important role in embryonic and fetal development as well as placental function [96-98]. Any defects during epigenetic reprogramming, including the imprinting process, may affect genotype and phenotype and are linked to embryonic abnormalities and diseases in later life [99]. As such, the periconceptional period, which involves the crucial process of epigenetic remodelling, makes the early oocyte or the preimplantation embryo vulnerable to perturbations that can have immediate and long-term consequences on the health of the offspring. For example, there is compelling evidence for a link between ARTs, manipulations in the periconceptional period, and epigenetic disorders (imprinting defects) [100]. A recent study has also shown that maternal nutritional status during the periconceptional period was associated with persistent epigenetic changes at human metastable epialleles [101].

This section has provided evidence that the periconceptional period encompasses many important events that determine health of the embryo and that any manipulation during this period, such as ART, can impact the processes of oocyte maturation, embryogenesis, fetal and postnatal development. It is important to understand that different types of ARTs are being used and thus that each type of ART involves different manipulations to the periconceptional period. 


\section{What Are the Different Procedures Involved in ARTs and How Do These Impact the Periconceptional Environment?}

\subsection{History, Procedures and Current Status of ARTs}

ARTs are manipulations during the periconceptional period in which the oocyte, sperm and/or zygote develop that apply laboratory or clinical techniques to gametes (sperm and ova) and/or embryos to establish pregnancy [102-104]. The history of ARTs dates back to 1890 when the first successful embryo transfer occurred in rabbits [105]. A live calf was successfully produced from embryo transfer 60 years later [106]. In 1973, two of the earliest human pregnancies occurred at the Queen Victoria Hospital in Melbourne but they lasted for less than a week [107]. These were chemical pregnancies identified by increasing plasma human chorionic gonadotropin (hCG) concentrations and provided the evidence that embryos produced from IVF could develop to the blastocyst stage and initiate implantation. The birth of the world's first test-tube baby, Louise Brown, occurred on 25 July 1978 at Oldham hospital in England, UK $[108,109]$. This was a landmark in the area of reproductive medicine and paved the way for scientific developments to improve implantation and pregnancy rates.

The use of ARTs has increased rapidly around the globe in recent years. In 2011, 588,629 treatment cycles were performed at clinics in 33 European countries, 151,923 cycles in the US and 66,347 cycles in Australia and New Zealand [110]. According to the European Society of Human Reproduction and Embryology, an estimated 5 million children have been conceived as result of ARTs [110]. The extensive usage of ARTs is attributed to increasing infertility rates in the population $[111,112]$. One of the reasons could be that women are considering pregnancy later in life. The average age of a first pregnancy has increased from 26.9 years in 1983 to 30.1 years in 2012 in Australia [113,114]. In 1991, around $23 \%$ of new mothers were aged over 30 years but this has risen to $37 \%$ in 2001 and $43 \%$ in 2011 [115]. Similar trends were observed in the USA and Canada where the average age of women having their first child increased from 21.4 years in 1970 to 25.8 years in 2012 and from 23.5 in mid 1960 s to 28.1 in 2008 , respectively [116,117]. There is evidence to suggest that fertility as well as fecundity declines with increasing age for both men and women [112,118-120]. Delayed child-bearing also results in increased time to conception and complications during pregnancy [121]. With recent advancements in both ARTs and clinical practice, coupled with the widespread availability of ART and improved success rates, there has been a rise in the number of couples that are experiencing problems with conception seeking treatment [122].

The improvements in ARTs have also benefited the livestock industry, which have resulted in great advancements in livestock production $[123,124]$. The introduction of reproductive technologies has increased production as well as reproduction of livestock animals with desired genetic characteristics [124,125]. They have also helped in overcoming reproductive problems, such as reducing generation intervals and preventing the spread of vertically transmitted diseases [126,127]. Livestock industries as a whole have scaled to new heights in terms of economic gains with the help of these reproductive technologies $[125,128]$.

The most widely used ART is IVF because it has the highest success rate per cycle, irrespective of the cause of the infertility [81]. It was developed to treat infertility associated with blocked Fallopian tubes and to treat other disorders related to infertility such as endometriosis, unexplained infertility, 
ovarian failure, ovulatory disorders and male infertility [129,130]. Gamete intraFallopian transfer (GIFT) and zygote intraFallopian transfer (ZIFT) were developed as alternative treatments to IVF in specific circumstances [82,131]. GIFT involves introduction of both egg and sperm in the Fallopian tube where fertilization and subsequent embryo development occurs [132-135]. GIFT treatment can be used as a treatment for sperm dysfunction, endometriosis or unknown infertility [136,137], but requires that at least one Fallopian tube is open. ZIFT involves removal of eggs followed by IVF with subsequent transfer of the embryo at the 2 cell stage into the Fallopian tube [138]. It can be used in cases of severe male infertility, immunologic infertility or unexplained infertility [138-141]. Other ARTs include artificial insemination (AI), intrauterine insemination (IUI) and intracytoplasmic sperm injection (ICSI), which are generally used in cases of male infertility and can be coupled with other ARTs, such as IVF, depending on the severity of the infertility (Table 2) [142,143].

\subsection{Periconceptional Manipulations Associated with ARTs}

A typical IVF treatment involves administration of FSH for controlled ovarian hyperstimulation over several days to induce the development of multiple follicles and the maturation of oocytes is induced by administration of hCG. This is followed by aspiration of mature oocytes from the ovarian follicles and insemination with a prepared sperm sample in vitro. The zygote that forms after fertilization of the oocyte and sperm is cultured in a nutritional medium for either 2-3 days to form a cleavage stage embryo or 5-6 days to form a blastocyst, which is then transferred to the uterine cavity for implantation (Table 2) [144,145]. In the past, more than one embryo was transferred to increase the chance of pregnancy and this has been associated with multiple pregnancies [146]. Twin pregnancies are at an increased risk of premature birth and its associated complications [147,148]. Therefore, transfer of a single embryo has been advocated to reduce the risk of multiple pregnancies [149]. With the transfer of a single embryo, a desirable pregnancy rate with fewer multiple pregnancies has been achieved [150]. However, even with the transfer of a single embryo, there are reports of increased twinning [151].

\subsection{In Vitro Embryo Culture: A Periconceptional Manipulation of the Nutritional Environment of the} Gametes and/or Zygote Associated with ARTs

An important component of many ARTs is the nutritional medium used for culturing the embryo [152,153]. The nutritional medium contains essential components required for optimal growth and to maintain the viability of the embryo at various stages of development [154]. The culture media from different clinics varies in composition but can be broadly classified into simple and complex media [155]. Simple culture medium includes Tryode's, Earle's T6, M16 and CZB, which contain balanced salt solutions and energy sources such as pyruvate, lactate and glucose. These are generally supplemented with serum from the patient or fetal cord serum because the media are known to lack of components that are essential for the growth and development of the embryo [156].

Efforts have been made to design media to match the dynamic in vivo environment and have led to the development of human tubal fluid (HTF) media [157]. HTF mimics the physiological environment of the human Fallopian tube and is based on the chemical composition of human tubal fluid $[153,157]$. The complex tissue culture medium contains amino acids, vitamins, nucleic acid precursors and metal ions and was originally designed to support somatic cells in culture, e.g., Ham's F-10, MEM and 
TCM-199 [155]. In recent years, media were designed with particular focus on each of the developmental stages of the embryo, broadly divided into pre-compaction and post-compaction stages or the cleavage and blastocyst stages [156].

The inclusion of human serum, which acts as a $\mathrm{pH}$ buffer and chelator for embryonic toxins such as "transitional and heavy metals" in addition to providing growth factors and nutrients such as amino acids and vitamins in the media, has been long debated [158-160]. The use of human serum in different culture media during the first 2 days of embryonic development in sheep leads to retarded growth but its inclusion during later stages leads to more blastocysts formations [161]. However, there are also reports of altered ultrastructure of the mitochondria and energy metabolism, epigenetic disorders including errors in imprinting, abnormal growth and gross abnormalities in several organ systems as a result of the addition of serum in the media during the early stages of embryonic development [162-165]. Recently, serum free culture media have been developed and proven to yield better results with increased blastocyst formation, higher implantation rates and reduced risk of contamination of the media by unknown components present in the serum [166,167].

We have described the complex maturation and developmental events of the oocyte and embryo that occur in the periconceptional period. These events must occur appropriately to allow gastrulation and the appropriate allocation of cells to each of the developing organ systems. We have also described the nutritional manipulations that the gametes and zygote are exposed to during the processes of ARTs (Table 2). Together, this information leads to questions about whether there is evidence that the periconceptional environment influences cardiovascular health as a fetus and into adulthood.

\section{What Is the Evidence that the Periconceptional Environment Influences Cardiovascular Health in Fetal Life and Adulthood?}

Cardiovascular disease is the leading cause of death worldwide causing an estimated 17.5 million deaths worldwide in 2012 and it is estimated to reach 23.3 million by 2030 [168,169]. Cardiovascular disease in adults is generally attributed to an unhealthy lifestyle during adulthood with most focus on poor diet, a sedentary lifestyle and smoking [170,171]. However, a growing body of evidence suggests that cardiovascular and metabolic disorders in adulthood may derive their origins from insults during prenatal life, including the periconceptional period [20,172]. Barker and colleagues coined the Fetal Origins of Health and Disease hypothesis, which stated that changes in the development of a permanent somatic structure or the "setting" of a physiological system by an early stimulus or insult during a critical period of development during which any manipulation of either environmental or nutritional factors can have long-lasting consequences on the physiology of the embryo and fetus [173,174].

Studies have shown that normal development of the mammalian cardiovascular system during the embryonic period as well as the transition from proliferative to hypertrophic cardiomyocytes growth during late gestation is dependent on the timely and accurate activation of many genes and signalling pathways [59,175]. Some of these signalling pathways are under epigenetic regulation such as DNA methylation and histone modifications [176,177]. Any abnormalities in the epigenetic control of these processes may result in cardiovascular malformation and susceptibility to disease in adult life $[178,179]$.

The heart is comprised of cardiomyocytes and non-myocytes including fibroblasts, endothelial cells, mast cells, vascular smooth muscle cells and the surrounding extracellular matrix [180,181]. During the 
first two thirds of gestation, heart growth is predominantly due to proliferation of mononucleated cardiomyocytes [182]. In humans and sheep, cardiomyocyte maturation, characterised by quiescence (absence of cardiomyocyte cytokinesis), occurs in the last third of gestation and subsequently heart growth in late gestation and postnatal life is primarily through cardiomyocyte hypertrophy [183,184]. In sheep, cardiomyocyte quiescence is easily identified due to almost all mononucleated cardiomyocytes becoming binucleated and subsequently terminally differentiated by birth [175,185-187]. In humans, the majority of cardiomyocytes remain mononucleated, however, it is widely accepted that only a tiny proportion of mononucleated cardiomyocytes undergo cytokinesis/proliferation after birth [188,189]. Recent studies have also provided evidence that cardiomyocytes continue to proliferate until almost 20 years of age [190]. In rodents, all cardiomyocytes are mononucleated at birth and retain the ability to proliferate and regenerate cardiac tissue after damage within the first week of life [191,192]. Like sheep, rodent cardiomyocytes become binucleated and terminally differentiated, however, unlike sheep and humans, this occurs rapidly between 4 and 12 days after birth [192-194]. Due to the limited potential for cardiomyocyte proliferation in postnatal life, the heart has a limited capacity to replace cardiomyocytes that are lost due to disease and aging. Subsequently, the number and the epigenetic profile of cardiomyocytes an individual is born with will have lifelong implications for cardiac health.

\section{Periconceptional Manipulations and Cardiovascular Disorders: Insights from Human and Animal Studies}

A series of epidemiological, clinical and experimental studies have shown that nutritional manipulations during the periconceptional period, may have adverse effects on cardiovascular health (Table 3) [59]. The most profound evidence was from the Dutch Winter Famine of 1944/45, which demonstrated that offspring exposed to malnutrition as an embryo or fetus during early gestation had elevated blood pressure in response to physiological stressors and $8.8 \%$ of those exposed during early gestation also had an increased risk of coronary heart disease compared to $0.9 \%$ and $2.5 \%$ of offspring whom were exposed to the famine in mid or late gestation respectively [195,196]. In another cohort periconceptional maternal tobacco smoking was associated with increased risk of congenital heart defects such as septal defects [197,198]. Likewise, alcohol consumption during the periconceptional period elevated conotruncal heart defects in offspring and that risk was associated with the frequency and the number of drinks consumed [199]. In a study examining the effects of the interaction of genetic factors and periconceptional nutritional manipulations on congenital heart defects, it was found that a low maternal dietary nicotinamide intake and usage of medicines such as antibiotics, anticonvulsants, anti-inflammatory, hormones and antimycotics during the periconceptional period independently increased the risk of congenital heart defects in the offspring by 2 fold [200]. 
Table 3. Maternal undernutrition during the periconceptional period alters cardiovascular development.

\begin{tabular}{|c|c|c|c|c|c|c|c|c|c|}
\hline Species & Periconceptional Manipulation & Time & $\begin{array}{l}\text { Blood } \\
\text { Pressure }\end{array}$ & $\begin{array}{l}\text { Baroreflex } \\
\text { Sensitivity }\end{array}$ & $\begin{array}{l}\text { Congenital } \\
\text { Heart Defects }\end{array}$ & $\begin{array}{l}\text { Risks for } \\
\text { Heart Diseases }\end{array}$ & $\begin{array}{l}\text { Heart } \\
\text { Weight }\end{array}$ & Vaso-Constriction & Vasodilation \\
\hline \multirow{3}{*}{ Human } & Undernutrition & Early gestation & $\uparrow[196]$ & $\mathrm{n} / \mathrm{a}$ & $\mathrm{n} / \mathrm{a}$ & $\uparrow[195]$ & $\mathrm{n} / \mathrm{a}$ & $\mathrm{n} / \mathrm{a}$ & $\mathrm{n} / \mathrm{a}$ \\
\hline & Alcohol consumption & $-30-+90$ days & $\mathrm{n} / \mathrm{a}$ & $\mathrm{n} / \mathrm{a}$ & $\uparrow[199]$ & $\mathrm{n} / \mathrm{a}$ & $\mathrm{n} / \mathrm{a}$ & $\mathrm{n} / \mathrm{a}$ & $\mathrm{n} / \mathrm{a}$ \\
\hline & $\begin{array}{l}\text { Low maternal dietary nicotinamide } \\
\text { and exposure to a range of medicines }\end{array}$ & $-30-+60$ days & $\mathrm{n} / \mathrm{a}$ & $\mathrm{n} / \mathrm{a}$ & $\uparrow[200]$ & $\mathrm{n} / \mathrm{a}$ & $\mathrm{n} / \mathrm{a}$ & $\mathrm{n} / \mathrm{a}$ & $\mathrm{n} / \mathrm{a}$ \\
\hline \multirow{3}{*}{ Rodent } & Protein restriction & $0-4.25$ days & $\uparrow[201]$ & $\mathrm{n} / \mathrm{a}$ & $\mathrm{n} / \mathrm{a}$ & $\mathrm{n} / \mathrm{a}$ & $\mathrm{n} / \mathrm{a}$ & $\mathrm{n} / \mathrm{a}$ & $\mathrm{n} / \mathrm{a}$ \\
\hline & \multirow{2}{*}{ Low protein diet } & $-3.5-0$ days & $\uparrow[202]$ & $\mathrm{n} / \mathrm{a}$ & $\mathrm{n} / \mathrm{a}$ & $\mathrm{n} / \mathrm{a}$ & $\mathrm{n} / \mathrm{a}$ & $\mathrm{n} / \mathrm{a}$ & $\downarrow$ \\
\hline & & $0-3.5$ days & $\uparrow[203]$ & $\mathrm{n} / \mathrm{a}$ & $\mathrm{n} / \mathrm{a}$ & $\mathrm{n} / \mathrm{a}$ & $\downarrow[203]$ & $\mathrm{n} / \mathrm{a}$ & $\mathrm{n} / \mathrm{a}$ \\
\hline \multirow{10}{*}{ Sheep } & \multirow{10}{*}{ Maternal undernutrition } & $-60-7$ days & $\uparrow[204]$ & $\mathrm{n} / \mathrm{a}$ & $\mathrm{n} / \mathrm{a}$ & $\mathrm{n} / \mathrm{a}$ & $\mathrm{n} / \mathrm{a}$ & $\mathrm{n} / \mathrm{a}$ & $\mathrm{n} / \mathrm{a}$ \\
\hline & & 1-30days & $\leftrightarrow[205]$ & $\downarrow[205]$ & $\mathrm{n} / \mathrm{a}$ & $\mathrm{n} / \mathrm{a}$ & $\mathrm{n} / \mathrm{a}$ & $\mathrm{n} / \mathrm{a}$ & $\mathrm{n} / \mathrm{a}$ \\
\hline & & 0-95 days & $\uparrow[206]$ & $\downarrow[206]$ & $\mathrm{n} / \mathrm{a}$ & $\mathrm{n} / \mathrm{a}$ & $\mathrm{n} / \mathrm{a}$ & $\mathrm{n} / \mathrm{a}$ & $\mathrm{n} / \mathrm{a}$ \\
\hline & & $-30-0$ days & $\mathrm{n} / \mathrm{a}$ & $\mathrm{n} / \mathrm{a}$ & $\mathrm{n} / \mathrm{a}$ & $\mathrm{n} / \mathrm{a}$ & $\mathrm{n} / \mathrm{a}$ & $\mathrm{n} / \mathrm{a}$ & $\downarrow[17]$ \\
\hline & & $-15-15$ days & $\mathrm{n} / \mathrm{a}$ & $\mathrm{n} / \mathrm{a}$ & $\mathrm{n} / \mathrm{a}$ & $\mathrm{n} / \mathrm{a}$ & $\mathrm{n} / \mathrm{a}$ & $\uparrow[17]$ & $\downarrow[17]$ \\
\hline & & 1-31days & $\uparrow[207]$ & $\mathrm{n} / \mathrm{a}$ & $\mathrm{n} / \mathrm{a}$ & $\mathrm{n} / \mathrm{a}$ & $\uparrow[207]$ & $\uparrow[207]$ & $\mathrm{n} / \mathrm{a}$ \\
\hline & & $-61-30$ days & $\mathrm{n} / \mathrm{a}$ & $\mathrm{n} / \mathrm{a}$ & $\mathrm{n} / \mathrm{a}$ & $\mathrm{n} / \mathrm{a}$ & $\uparrow[11]$ & $\mathrm{n} / \mathrm{a}$ & $\mathrm{n} / \mathrm{a}$ \\
\hline & & $-61-0$ days & $\mathrm{n} / \mathrm{a}$ & $\mathrm{n} / \mathrm{a}$ & $\mathrm{n} / \mathrm{a}$ & $\mathrm{n} / \mathrm{a}$ & $\downarrow[208]$ & $\mathrm{n} / \mathrm{a}$ & $\mathrm{n} / \mathrm{a}$ \\
\hline & & $-61-30$ days & $\mathrm{n} / \mathrm{a}$ & $\mathrm{n} / \mathrm{a}$ & $\mathrm{n} / \mathrm{a}$ & $\mathrm{n} / \mathrm{a}$ & $\downarrow[208]$ & $\mathrm{n} / \mathrm{a}$ & $\mathrm{n} / \mathrm{a}$ \\
\hline & & $-2-30$ days & $\mathrm{n} / \mathrm{a}$ & $\mathrm{n} / \mathrm{a}$ & $\mathrm{n} / \mathrm{a}$ & $\mathrm{n} / \mathrm{a}$ & $\downarrow[208]$ & $\mathrm{n} / \mathrm{a}$ & $\mathrm{n} / \mathrm{a}$ \\
\hline
\end{tabular}

$\uparrow=$ increase, $\downarrow=$ decrease, $\leftrightarrow=$ no difference, $\mathrm{n} / \mathrm{a}=$ not applicable (because not included in the reported study results). 
Animal models have been useful in identifying the underlying mechanisms that are responsible for the association between nutritional manipulation in the periconceptional period and cardiovascular health in adult life (Table 3). Maternal protein restriction during the preimplantation period in rats resulted in a reduced number of cells in the blastocyst stage, a reduction in birth weight, accelerated postnatal growth and elevated systolic blood pressure (SPB) in postnatal life [201]. Maternal protein restriction, specifically during oocyte maturation, led to hypertension in the adult offspring [202]. Similarly maternal protein restriction from 0 to 3.25 days after mating reduced heart weight and increased SPB in offspring in postnatal life [203]. In addition, the heart to body weight ratio in females was negatively correlated with SBP measured at 9, 15, and 21 weeks [203].

In sheep, maternal undernutrition during the periconceptional period extending from 60 days prior to conception until 7 days after fertilization resulted in an increase in arterial blood pressure and rate pressure product in twins, but not singleton fetuses in late gestation (term, 150 days) [204]. There was altered baroreflex sensitivity in response to angiotensin II infusion at 1 year of age as a result of global energy restriction from the day of conception until 30 days of gestation [205]. Maternal undernutrition extending from 0 to 95 days gestation resulted in an increase in prefeeding basal blood pressure and blunted baroreflex in response to norepinephrine infusion at 3 years of age [206]. In another study undernutrition during the 30 days before conception resulted in diminished endothelium-dependent and independent vasodilatation in third order femoral arteries [17]. An undernutrition regime from 15 days prior to until 15 days after conception resulted in greater vasoconstrictor responses in both left anterior descending coronary and left internal thoracic arteries [17]. There was attenuated endothelium-dependent and independent vasodilatation in third order femoral arteries as well as reduced endothelium-independent vasodilation in both the left anterior descending coronary and renal arteries [17]. There was an increase in blood pressure in response to frusemide, a loop diuretic used to activate renin angiotensin system, in 1.5 year old lambs of ewes that were undernourished between 1 and 31 days of gestation. At 2.5 years, these lambs had increased interventricular septal wall thickness, mean left ventricular wall thickness and increased constriction to acetylcholine in isolated coronary arteries [207]. Furthermore, offspring born to ewes that were undernourished from -61 days before until 30 days after conception had increased fetal heart weight relative to body weight in late gestation [11]. In contrast, relative heart weight was reduced in the offspring of ewes that were undernourished from 60 days prior to conception, 60 days before and 30 days after conception and 2 days before and after conception [208].

The above studies provide evidence that nutritional manipulation in the periconceptional period has adverse effects on the cardiovascular system, which might predispose an individual to an increased risk of cardiovascular disease.

\section{What Is the Evidence that ARTs Influence Cardiovascular Health Before and After Birth?}

Studies have demonstrated that not only insults during the periconceptional period in vivo (Table 3), but also those that occur in vitro during this critical period of development can have detrimental effects on cardiovascular development [13,59,204,209,210]. This highlights the importance of understanding the long-term effects of ARTs on cardiovascular development. There are reports of altered fetal and postnatal growth and development as a result of in vitro nutritional manipulations during the periconceptional 
period in humans, rodents, cows and sheep [211-213]. These reports have raised serious questions about the safety of ARTs for both the immediate and long-term health of individuals conceived through ARTs. Among the long-term health outcomes, cardiovascular health remains the most important concerns due to the sensitivity of heart development to perturbations during the periconceptional period $[20,59,214,215]$.

A recent study reported the incidence of cardiac malformations using different search terms related to cardiac malformations and/or ARTs in the Medline database for the years 1999 to 2012. The search returned data on 32,000 births (21,000 naturally conceived; 11,000 conceived through ART) [216]. Cardiac malformations occurred in 1.8\% (198 cases) of births conceived through ART compared to $0.4 \%$ (88 cases) of births in the general population [216]. Comparing the incidence of specific forms of cardiovascular disorders from a total of 11,000 pregnancies in ART children and 21,000 pregnancies in naturally conceived (NC) children respectively, there were 58 cases $(0.53 \%)$ of atrial septal defect in ART vs. 26 cases $(0.12 \%)$ in NC, 37 cases $(0.34 \%)$ of changes in the interventricular septum in ART vs. 18 cases $(0.09 \%)$ in NC, 20 cases $(0.18 \%)$ of coarctation of the aorta $v s .13$ cases $(0.06 \%)$ in NC, 18 cases $(0.16 \%)$ of aortic stenosis in ART vs. 11 cases $(0.05 \%)$ in NC, 11 cases $(0.10 \%)$ of tetralogy of Fallot in ART vs. 5 cases $(0.02 \%)$ in NC, 6 cases $(0.05 \%)$ of stenosis of the pulmonary trunk in ART vs. 5 cases $(0.02 \%)$ in $\mathrm{NC}$ and 48 cases $(0.44 \%)$ of other non-specified cardiac defects in ART and vs 10 cases $(0.05 \%)$ in NC. [216]. These data suggest that compared to natural conception, there is an increased risk of cardiovascular malformations in children conceived through ART.

\subsection{Congenital Heart Defects in Human Population}

Many studies have reported the incidence of congenital heart defects in children conceived through ARTs (Table 4). In the first report of a relationship between ART and congenital heart defects, Lancaster et al. found that there were 4 cases of transposition of the great arteries in the offspring conceived through IVF [217]. Several studies have also confirmed these findings. For example, a significant increase in overall congenital heart defects in children conceived through IVF compared to children with unassisted conception was reported in different population based studies [218-221]. The increase in cardiovascular defects also remained significant when the analysis was performed in only singletons [218,219]. Another population based study in Finland compared the risk of congenital defects in IVF and other ART categories with the control population based on infant sex and multi-fetal pregnancies and found an increase in congenital heart defects in the female offspring of singleton pregnancies in other ART categories group [222].

A case-control study using the California Linked Birth Cohort Dataset found an increased risk of major cardiac malformations in $4.8 \%$ of births from ART (IVF with or without ICSI, GIFT) compared to $3.0 \%$ in the matched control population [50]. After adjusting for maternal and infant factors such as maternal age, parity, race, multiple births, infant sex and year of birth, the rate of congenital heart defects was significantly higher in the infants born after ARTs [50]. When the heart defects in singleton and multi-fetal ART pregnancies were compared, the multi-fetal pregnancies had an increased risk of congenital cardiac defects than the singleton pregnancies [50]. An increased rate of congenital malformations in infants conceived by ART was also reported in a retrospective cohort study in Ottawa [223]. In a cross-sectional descriptive study in Iran, 8 cases of IVF pregnancies with congenital heart defects were reported in a population of 400 ART children [224]. 
In addition to evidence that ARTs increase the risk of cardiac defects, studies have identified specific congenital cardiac defects associated with ARTs (Table 4). The prevalence of congenital heart malformations such as atrial septal defects and ventricular septal defects was four-fold higher in children born after IVF than the matched controls in a Finnish population based cohort study [225] In a cross-sectional study in Iran, children conceived through ARTs had increased risk of ventricular and septal defects [226]. A population based study analysed specific cardiovascular defects in the Danish population study and reported a significant increase in the prevalence of a single umbilical artery in IVF children when compared to controls [221]. In another population based, multicenter case controlled study of birth defects in the United States, the singleton births resulting from IVF and ICSI were at increased risk of septal heart defects, including ventricular septal defect, atrial septal defect and other non-specified defects compared to unassisted conception [227]. Using data from a Swedish database for the period 1982-2001, it was found that in addition to an overall risk of congenital heart diseases, the association between ARTs and congenital heart defects became more marked when the analysis was restricted to major cardiac defects such as common arterial trunk, double outlet right or left ventricle, D- and L-transposition of great vessels, double inlet left ventricle, endocardial cushion defect, tetralogy of Fallot, tricuspid atresia or stenosis, Ebstein's anomaly, hypoplastic left heart syndrome, aortic valve atresia, specified anomalies of the great veins or to septal defects [228]. In another study, which used the Swedish database for the period 2001-2007 found an increased risk of cardiovascular malformations, which was similar to the data from the same database for the period (1982-2001) [229]. The study also reported an increased risk of septal and ventricular defects but the risk was lower during the period 2001-2007 compared to the previous time period [229].

Based on a case-control study using data from Paris Registry of Congenital Malformations, it was found that cases of congenital heart diseases were more likely to be born as a result of ARTs when compared to controls [230]. The study investigated three major categories of congenital heart defects (all congenital heart diseases combined, congenital heart diseases without chromosomal abnormalities and congenital heart diseases without chromosomal abnormalities (excluding isolated ventricular septal defects)) and it was found that there was also a $40 \%$ increase in the overall risk of congenital heart disease without chromosomal abnormalities in infants conceived through ARTs after adjusting for maternal age, socioeconomic factors and year of birth [230]. Specific congenital malformations such as malformations of the outflow tracts and ventriculoarterial connections, cardiac neural crest defects and double outlet right ventricle were significantly associated with ARTs [230]. The study also reported that IVF and ICSI were associated with an increased risk of congenital heart disease, but not ovulation induction alone [230]. Another case-control study using data from the population-based Paris Registry of Congenital Malformations, and a prospective cohort study of congenital heart disease in children (EPICARD) investigated the association between ARTs and four specific forms of congenital heart diseases (hypoplastic left heart syndrome, transposition of great arteries, tetralogy of Fallot, and coarctation of the aorta) [231]. The study found that ARTs (IVF, ICSI and ovulation induction alone) were associated with a 2.4-fold increased risk of tetralogy of Fallot, after adjusting for maternal age, occupation, geographic origin, paternal age and year of birth [231]. There was no significant association between ART and the other 3 congenital malformations [231]. 


\subsection{Evidence of Risk Factors for Long-Term Cardiovascular Outcomes in Humans}

The increased risk of cardiovascular defects at birth provides a strong justification for follow-up studies to investigate the effect of the procedures involved in ARTs on the long-term consequence on cardiovascular health outcomes. What is not known is whether ARTs are associated with an increased risk for clinical cardiovascular endpoints due to the young age of the ART population in humans. However, emerging studies have provided evidence for an association of ARTs with increased risk factors for cardiovascular disease (Table 5).

Fetuses from ART pregnancies had altered cardiac morphometry and impaired systolic and diastolic function compared to controls [232]. When they were assessed during neonatal life, an increased diastolic blood pressure percentile, aortic and carotid intermedia thickness was reported in ART children compared to controls [232]. During infancy, children from ART pregnancies had increased right atrial size, right ventricular wall thickness, aortic wall thickness, SBP and heart rate as well as decreased shortening fraction, right sphericity index and systolic and diastolic function [232]. This evidence suggests that cardiovascular remodelling was present in fetal life and persisted into infancy in ART children and this may suggest an increased risk of cardiovascular disease in later life.

A study has also shown that the children conceived through IVF had increased SBP and DBP at a mean age of 12.3 years [233]. Furthermore, there was an association between early childhood weight gain and SBP during follow-up [234], which is an important risk factor for cardiovascular disease in later life [235,236]. Similarly, in a cross-sectional study in Athens, a higher SBP and DBP deviation score was reported in ARTs children compared to naturally conceived children in the age group 4-14 year [237].

Vascular functions were studied in ART conceived children at around 12 years of age and a $25 \%$ reduction in flow-mediated dilation of the brachial artery evoked by reactive hyperemia was reported but no difference was observed with endothelium-independent vasodilation evoked by nitroglycerine [238]. This finding is suggestive of endothelial dysfunction in ART offspring, which is an important and early marker for the development of atherosclerosis in later life and has previously been shown to be present in healthy children whom were at increased risk of cardiovascular diseases [239-242]. The study also found a significant faster carotid femoral pulse wave velocity, which is widely used as a gold standard for measuring arterial stiffness as well as an increased carotid intima-media thickness, both of which are markers for development of atherosclerosis and independent risk factors for cardiovascular disease [238,243-245]. In addition, ART children had 30\% higher pulmonary pressure at higher altitude [238]. The findings from this study provide evidence for both systemic and pulmonary vascular dysfunction in ART children, which could lead to adverse cardiovascular outcomes in later life [238]. Most importantly, it was reported that the vascular dysfunctions were not related to parental factors but more likely due to the ART procedure itself. 
Table 4. Congenital heart defects that result from ART.

\begin{tabular}{|c|c|c|c|}
\hline Study Type; Population; Year & Sample Size $(N)$ & Congenital Heart Defects & Reference \\
\hline $\begin{array}{c}\text { Registry of IVF and GIFT } \\
\text { pregnancies in Australia and } \\
\text { New Zealand }\end{array}$ & IVF-1694 & 4 -cases of transposition of great arteries $(p=0.0034)$. & [217] \\
\hline $\begin{array}{l}\text { Population based study; } \\
\text { Children conceived by IVF or } \\
\text { IUI at the University of Iowa; } \\
\text { 1989-2002 }\end{array}$ & $\begin{array}{c}\text { IVF-1462 } \\
\text { IUI-343 } \\
\text { Controls-8422 }\end{array}$ & $\begin{array}{l}\text { - Increased cardiovascular defects among the infants conceived through IVF when compared with } \\
\text { control children }(p=0.002) \text { but no significant increase in cardiovascular defects in IUI infants. } \\
\text { - Significant increase in cardiovascular defects was also reported when the analysis was done only } \\
\text { in singletons }(p=0.003) \text {. }\end{array}$ & [218] \\
\hline $\begin{array}{l}\text { Population-wide cohort study; } \\
\text { South Australian Perinatal } \\
\quad \text { Statistics Collection; } \\
\text { January 1986-December } 2002\end{array}$ & $\begin{array}{c}\text { ART-6163 } \\
\text { Controls-302,811 }\end{array}$ & $\begin{array}{l}\text { - There was significant association between the use of ARTs and risks of multiple cardiovascular } \\
\text { defects for singleton births (1.8\% vs. 1.2\%; adjusted OR } 1.36(1.08-1.72)) \text {. } \\
\text { - (Adjusted for maternal age, parity, fetal sex, year of birth, maternal race or ethnic group, maternal } \\
\text { country of birth, maternal conditions in pregnancy, maternal smoking during pregnancy, } \\
\text { socioeconomic status, and maternal and paternal occupation) }\end{array}$ & [219] \\
\hline $\begin{array}{l}\text { Population based study; } \\
\text { Reproductive Technology } \\
\text { Register; 1993-1997 }\end{array}$ & $\begin{array}{c}\text { IVF-837 } \\
\text { ICSI-301 } \\
\text { Controls-4000 } \\
\end{array}$ & $\begin{array}{l}\text { Increased prevalence of cardiovascular defects in children conceived with IVF, but not those } \\
\text { conceived with ICSI compared to controls }(p<0.001) .\end{array}$ & [220] \\
\hline $\begin{array}{l}\text { Population based study; } \\
\text { National professional Perinatal } \\
\text { and Neonatal Registers; } \\
\quad 1995-1996\end{array}$ & $\begin{array}{c}\text { IVF-4224 } \\
\text { Controls-314,605 }\end{array}$ & $\begin{array}{c}\text { - Increased risk of overall cardiovascular malformations (OR 1.56, 95\% CI 1.10-2.2). } \\
\text { - After analysing specific cardiovascular malformations, an increased risk of single umbilical artery } \\
\text { was reported (OR 1.93, 95\% CI 1.11-3.35). } \\
\text { (Adjusted for maternal age, parity and ethnicity) }\end{array}$ & [221] \\
\hline $\begin{array}{l}\text { Population based study; } \\
\text { Medical Birth Register, } \\
\text { Finland; 1996-1998 }\end{array}$ & $\begin{array}{l}\text { IVF-4559 } \\
\text { Other ARTs-4467 } \\
\text { Controls-27,078 }\end{array}$ & $\begin{array}{l}\text { - Increased risk of congenital heart defects in both IVF }(p=0.042) \text { and ART categories }(p=0.021) \\
\text { compared to controls when expressed as prevalence of birth defects per 10,000 infants. } \\
\text { - The singleton girls in other ART categories had an increased incidence of congenital heart defects } \\
\text { when analysis was done for gender and multiplicity (adjusted OR 1.52, 95\% CI 1.01-2.28). } \\
\text { (Adjusted for age) }\end{array}$ & \\
\hline
\end{tabular}


Table 4. Cont.

\begin{tabular}{|c|c|c|c|}
\hline Study Type; Population; Year & Sample Size $(N)$ & Congenital Heart Defects & Reference \\
\hline $\begin{array}{l}\text { Case-control; California Patient } \\
\text { Discharge Linked Birth Cohort } \\
\text { Database Dataset; } 2006 \text { to } 2007\end{array}$ & $\begin{array}{c}\text { ART-4795 } \\
\text { Controls-46,025 }\end{array}$ & $\begin{array}{c}- \text { Born after ARTs (adjusted OR 1.41, 95\% CI 1.22-1.64). } \\
\text { - The multi-fetal pregnancies were at increased risk of congenital cardiac defects compared to } \\
\text { singleton (adjusted OR 1.56,95\% CI 1.31-1.85). } \\
\text { (Adjusted for maternal and infant factors such as maternal age, parity, race, multiple births, infant sex } \\
\text { and year of birth) }\end{array}$ & {$[50]$} \\
\hline $\begin{array}{c}\text { Retrospective cohort study: } \\
\text { Ottawa; Fertility Centre; } \\
\text { 1996-2005 }\end{array}$ & $\begin{array}{c}\text { ART-1044 } \\
\text { Controls-1910 }\end{array}$ & $\begin{array}{l}\text { - Higher rate of congenital heart defects in infants conceived by ART than controls } \\
\text { (adjusted OR 4.58, 95\% CI 1.48-14.18). } \\
\text { (Adjusted for maternal age, plurality, year of delivery, catchment area, gestational weight gain, parity, } \\
\text { maternal smoking, medical history, Rh. negative, pelvic surgery) }\end{array}$ & [223] \\
\hline $\begin{array}{l}\text { Cross-sectional descriptive } \\
\text { study; Royan Institute, Tehran; }\end{array}$ & ART-400 & 8 cases $(2 \%)$ of defects in cardiovascular system. & [224] \\
\hline $\begin{array}{l}\text { Population based cohort study; } \\
\text { IVF Outpatient Clinic, } \\
\text { University of Oulu and } \\
\text { Infertility Clinic of the Family } \\
\text { Federation of Finland and Oulu } \\
\text { Controls- Finnish Medical } \\
\text { Birth Register; } \\
\text { 1990-1996 }\end{array}$ & $\begin{array}{c}\text { IVF-304 } \\
\text { Controls-569 }\end{array}$ & 4 fold increase in atrial septal and ventricular septal defects (OR 4.0, 95\% CI 1.4-11.7). & {$[225]$} \\
\hline $\begin{array}{l}\text { Historical cohort study; Child } \\
\text { Health and Development } \\
\quad \text { Research Centre; } \\
\text { January 2008-December } 2010\end{array}$ & $\begin{array}{c}\text { ART-326 } \\
\text { Controls-652 }\end{array}$ & Increased risks of cardiovascular malformations in ART children (1.07\% vs. $1.53 \%)$. & [226] \\
\hline
\end{tabular}


Table 4. Cont.

\begin{tabular}{|c|c|c|c|}
\hline Study Type; Population; Year & Sample Size $(N)$ & Congenital Heart Defects & Reference \\
\hline $\begin{array}{l}\text { Population based, } \\
\text { multicenter case-control study, } \\
\text { National Birth Defects } \\
\text { Prevention Study; } \\
\text { October 1997-December } 2003\end{array}$ & $\begin{array}{c}\text { Cases-9584 } \\
\text { (with birth defects) } \\
\text { Controls-4792 } \\
\text { (no birth defects) }\end{array}$ & $\begin{array}{l}\text { - Increased risk of overall septal heart defects (ventricular septal defect, atrial septal defect and } \\
\text { other non-specified defects) in singleton infants born after ART compared to unassisted } \\
\text { conception (adjusted OR 2.1,95\% CI 1.1-4.0). } \\
\text { - Increased risk of atrial septal defect secundum/ not otherwise specified defects (adjusted OR 3.0, } \\
\text { 95\% CI 1.5-6.1), and ventricular septal defect plus atrial septal defect (adjusted OR 2.8, 95\% CI } \\
\text { 1.2-7.0) in singleton infants compared to unassisted conception. } \\
\text { (Adjusted for maternal age, study center, parity, family income and prematurity) }\end{array}$ & {$[227]$} \\
\hline $\begin{array}{l}\text { Population based study; } \\
\text { Swedish Medical Birth } \\
\text { Register, Swedish Registry of } \\
\text { Congenital Malformations, } \\
\text { and Swedish Hospital } \\
\text { Discharge Register; } \\
\text { 1982-March 31, 2001 }\end{array}$ & $\begin{array}{c}\text { ART-16,280 } \\
\text { Controls-2,039,943 }\end{array}$ & $\begin{array}{l}\text { - An overall increased risk of congenital heart defects in infants conceived through ART was } \\
\text { observed compared to controls; (adjusted OR 1.7, 95\% CI 1.5-2.0). } \\
\text { - A stronger association between ARTs and congenital heart defects when the analysis was } \\
\text { restricted to major cardiac defects such as common arterial trunk, double outlet right or left } \\
\text { ventricle, d- and } 1 \text { transposition of great vessels, double inlet left ventricle, endocardial cushion } \\
\text { defect, tetralogy of Fallot, tricuspid atresia or stenosis, Ebstein's anomaly, hypoplastic left heart } \\
\text { syndrome, aortic valve atresia and specified anomalies of great veins } \\
\text { (adjusted OR 2.1,95\% CI 1.6-2.8) or to septum defects in the absence of non-cardiovascular } \\
\text { defects (adjusted OR 2.6, 95\% CI 2.2-3.1). } \\
\text { (Adjusted for year of birth) }\end{array}$ & {$[228]$} \\
\hline $\begin{array}{l}\text { Population based study; } \\
\text { Swedish Medical Birth } \\
\text { Register, Swedish Registry of } \\
\text { Congenital Malformations, } \\
\text { and Swedish Hospital } \\
\text { Discharge Register; } \\
31 \text { March 2001-1 January } 2007\end{array}$ & $\begin{array}{c}\text { IVF-15,570 } \\
\text { Controls-5,689,157 }\end{array}$ & $\begin{array}{l}\text { - An overall increased risk of cardiovascular defects in infants conceived through ART was } \\
\text { observed compared to controls (adjusted OR 1.30, 95\% CI 1.13-1.49). } \\
\text { - Compared to a previous study using the same database from 1982-2001, it was reported that both } \\
\text { the studies had increased risk of atrial septal defects and ventricular septal defects } \\
\text { (OR 3.16, 95\% CI 2.71-3.67) vs. (OR 2.35, 95\% CI 2.09-2.64). } \\
\text { (Adjusted for year of birth, maternal age, parity, smoking, and body mass index) }\end{array}$ & [229] \\
\hline
\end{tabular}


Table 4. Cont.

\begin{tabular}{|c|c|c|c|}
\hline Study Type; Population; Year & Sample Size $(N)$ & Congenital Heart Defects & Reference \\
\hline $\begin{array}{l}\text { Case control study; Paris } \\
\text { Registry of Congenital } \\
\text { Malformations; 1987-2006 }\end{array}$ & $\begin{array}{l}\text { Cases-5493 } \\
\text { (with congenital heart defects) } \\
\text { Malformed controls-3487 } \\
\text { (malformations not previously } \\
\text { associated with ART) }\end{array}$ & $\begin{array}{l}\text { - Cases from congenital heart diseases were more likely to be conceived through ARTs than other } \\
\text { malformed controls (4.7\% vs. 3.6\%; } p=0.008 \text { ). } \\
\text { - Infants conceived through ART have } 40 \% \text { increase in the overall risk of congenital heart disease } \\
\text { without chromosomal abnormalities. } \\
\text { - Significant associations between ARTs and specific congenital malformations such as } \\
\text { malformations of the outflow tracts and ventriculoarterial connections } \\
\text { (adjusted OR 1.7, 95\% CI 1.2-2.4) as well as cardiac neural crest defects and double outlet right } \\
\text { ventricle (adjusted OR 1.7, 95\% CI 1.1-2.7). } \\
\text { (Adjusted for maternal age, geographic origin, occupation, and year of birth) }\end{array}$ & [230] \\
\hline $\begin{array}{l}\text { Case-control; Paris Registry of } \\
\text { Congenital Malformations; } \\
\text { 1987-2009. Prospective cohort } \\
\text { study, congenital heart disease } \\
\text { in children (EPICARD); } \\
\text { 2005-2008 }\end{array}$ & $\begin{array}{l}\text { Case- } 1583 \\
\text { (with congenital heart defects) } \\
\text { Malformed controls-4104 } \\
\text { (malformations not previously } \\
\text { associated with ART) }\end{array}$ & $\begin{array}{l}\text { - ARTs were associated with a 2.4-fold increased risk of tetralogy of Fallot } \\
\text { (adjusted OR 2.4,95\% CI 1.5-3.7). } \\
\text { - No significant association between ART and hypoplastic left heart syndrome, transposition of } \\
\text { great arteries and coarctation of the aorta malformations. } \\
\text { (Adjusted for maternal age, occupation, geographic origin, paternal age and year of birth) }\end{array}$ & [231] \\
\hline
\end{tabular}

OR, odds ratio; CI, confidence intervals. 
Table 5. Cardiovascular risk factors in fetal and postnatal life.

\begin{tabular}{ll}
\hline Study Type; Population; Year & Sample Size $(\boldsymbol{N})$; Age(s) \\
\hline Prospective cohort study; & ART-100 \\
Maternal-Fetal Medicine Unit, & Controls-100 \\
Spain. & $28-30$ weeks gestation, \\
& 1 month, \\
& 6 months
\end{tabular}

\section{Cardiovascular Risk Factors}

- Fetuses (28-30 weeks gestation) - Increased left atrial area (1.48vs. 1.35; $p<0.001)$, right atrial area (1.60 vs. 1.46; $p<0.001)$, interventricular wall thickness $(2.7 v s .2 .4 ; p<0.001)$ and right wall thickness (3.2 vs. 2.8; $p=0.038)$, decreased left $(1.71 v s .1 .77 ; p=0.003)$ and right (1.37 vs. $1.58 ; p<0.001)$ ventricular sphericity indexes.

6 months

- For systolic function, there was decreased left ejection fraction (63 vs. 69; $p<0.001)$, mitral ring displacement (4.2 vs. 4.7; $p<0.001)$, tricuspid ring displacement (5.5 vs. 6.5; $p<0.001)$, mitral systolic annular peak velocity (6 vs. 6.9; $p=0.038)$.

- For diastolic function, there was decreased mitral ventricular inflow in early diastole displacement time (63 vs.73; $p=0.002)$, tricuspid ventricular inflow in early diastole deceleration time ( 51 vs. $64 ; p=0.001)$, mitral annular peak velocity in early diastole (7 vs. 7.6; $p=0.049)$, tricuspid annular peak velocity in early diastole $(8 v s .8 .3 ; p=0.002)$ and isovolumic relaxation time ( $48 v s .30 ; p=0.003)$.

- Neonates (1 month) - Increased DBP percentile (71 vs. $55 ; p=0.042)$, aortic mean intima-media thickness $(0.16 v s .0 .12 ; p=0.011)$, aortic maximum intima-media thickness (0.19 vs. 0.14; $p=0.011)$, carotid mean intima-media thickness $(0.07 v s .0 .06 ; p=0.035)$ and carotid maximum intima-media thickness $(0.09 \mathrm{vs} .0 .07 ; P=0.035)$ relative to body weight.

- Infant (6 months) - Increased right atrial area (2.70 vs. 2.50; $p=0.005)$, right wall thickness (3.21 vs. 2.59; $p=0.019)$, and decreased right ventricular sphericity index (1.82 vs. $1.91 ; p=0.010)$.

- For systolic function, there was decreased left shortening fraction (29vs. 36; $p<0.001)$, mitral ring displacement (9.4 vs. 10.8; $p<0.001)$, tricuspid ring displacement (13.1 vs. $16.3 ; p<0.001)$ and increased heart rate $(141 v s .132 ; p=0.002)$.

- For diastolic function, there was decreased mitral ventricular inflow in early diastole displacement time (63vs. 66; $p=0.014$ ), tricuspid ventricular inflow in early diastole deceleration time (52 vs. 62; $p<0.001)$ and increased isovolumic relaxation time (63 vs. 50;

$$
p<0.001) \text {. }
$$

- Increased SBP (83 vs. 74; $p<0.001)$, aortic mean intima-media thickness (1.8 vs. 1.4; $p<0.001)$ and aortic maximum intima-media thickness (2.0 vs. 1.6; $p<0.001)$ relative to body weight. 
Table 5. Cont.

\begin{tabular}{|c|c|c|c|}
\hline Study Type; Population; Year & Sample Size $(N) ; \operatorname{Age}(s)$ & Cardiovascular Risk Factors & Reference \\
\hline $\begin{array}{l}\text { Retrospective cohort study; } \\
\text { OMEGA study, VU university } \\
\text { Medical centre, Netherland; } \\
\text { 1980-1995 }\end{array}$ & $\begin{array}{c}\text { IVF-225 } \\
\text { Controls-225 } \\
8-18 \text { year (mean age } 12 \text { year) }\end{array}$ & $\begin{array}{l}\text { Increased SBP and DBP pressure in children conceived through IVF compared to control population } \\
\text { at a mean age of } 12.3(109 \pm 11 \mathrm{vs.} 105 \pm 10 \mathrm{mmHg}, p<0.001 ; \text { and } 61 \pm 7 \mathrm{vs} .59 \pm 7 \mathrm{mmHg} \text {, } \\
\qquad p<0.001) \text {, respectively. }\end{array}$ & [233] \\
\hline $\begin{array}{l}\text { Cross- sectional, case-control } \\
\text { study; IVF cases-IVF section, } \\
\text { Department of Obstetrics and } \\
\text { Gynaecology; University of } \\
\text { Athens Controls-Aghai Sophia } \\
\text { Children's hospital; } 1990-1996\end{array}$ & $\begin{array}{l}\text { IVF-106 } \\
\text { Controls-68 } \\
\text { 4-14 year }\end{array}$ & $\begin{array}{l}\text { Increased SBP and DBP standard deviation score }(0.3 \text { vs. }-0.3, p<0.001 ; 0.7 \text { vs. } 0.2 p<0.001) \text { in } \\
\text { children conceived through IVF. }\end{array}$ & [237] \\
\hline $\begin{array}{l}\text { Clinical Trial; Swiss children } \\
\text { IVF and Control siblings of } \\
\text { IVF children; } \\
\text { October 2007-April } 2010\end{array}$ & $\begin{array}{l}\text { ART-65 } \\
\text { Controls-57 } \\
\text { Mean-11 year }\end{array}$ & $\begin{array}{l}\text { Smaller flow mediated dilation of the brachial artery }(6.7 \pm 1.6 \mathrm{vs} .8 .6 \pm 1.7 \% ; p<0.0001) \text {, faster } \\
\text { carotid-femoral pulse wave velocity }(7.8 \pm 2.4 \mathrm{vs} .6 .5 \pm 1.3 \mathrm{~m} / \mathrm{s} ; p<0.001) \text {, increase in carotid } \\
\text { intima-media thickness }(410 \pm 30 \mathrm{vs.} 370 \pm 20 \mu \mathrm{m} ; p<0.0001) \text {, higher systolic pulmonary artery } \\
\text { pressure }(39 \pm 11 \mathrm{vs.} 30 \pm 9 \mathrm{mmHg} ; p<0.0001) \text { in ART children compared to control children. } \\
\text { An inverse relationship existed between pulmonary artery pressure and flow mediated dilation } \\
(r=-0.30, p=0.001) .\end{array}$ & [238] \\
\hline
\end{tabular}




\subsection{Evidence of Cardiovascular Defects from Animal Models of ARTs}

Animal models of ARTs have been instrumental in providing evidence for further links between ARTs and an increased risk of cardiovascular defects (Table 6).

Table 6. Cardiovascular risk factors from animal models of ARTs.

\begin{tabular}{|c|c|c|c|}
\hline Species & $\operatorname{Age}(\mathbf{s})$ & Cardiovascular Risk Factors & Reference \\
\hline \multirow{4}{*}{ Sheep } & $\begin{array}{l}61 \text { day gestation } \\
125 \text { day gestation }\end{array}$ & $\begin{array}{l}\text { Increased allometric growth coefficients of heart at } 61 \text { and } 125 \text { days } \\
\text { of gestation. }\end{array}$ & [163] \\
\hline & 125 day gestation & $\begin{array}{l}\text { Increased absolute }(25.8 \pm 8.9 v s .19 .0 \pm 4.1, p=0.004) \text { and relative heart } \\
\text { weight }(6.5 \pm 1.05 \text { vs. } 5.7 \pm 0.76, p=0.022) \text { in in vitro embryo culture } \\
\text { group when serum was supplemented during precompaction period. }\end{array}$ & [246] \\
\hline & 125 day gestation & $\begin{array}{l}\text { Inverse relation between heart weight and IGFR2 gene expression } \\
(r=-0.675, p<0.001) \text { and loss of methylation of IGF2R in embryo } \\
\text { culture group when compared to control group. }\end{array}$ & {$[58]$} \\
\hline & 125 day gestation & $\begin{array}{l}\text { A strong inverse relation between heart weight and IGFR2 gene expression } \\
\text { in the in vitro embryo culture groups }(r=-0.73, p<0.001) \text {. }\end{array}$ & [247] \\
\hline \multirow{3}{*}{ Cows } & $\begin{array}{l}222 \text { day gestation } \\
(7 \text { months })\end{array}$ & $\begin{array}{c}\text { Increased heart girth }(56.5 \pm 1.2 v s .52 .4 \pm 0.9, p=0.01) \text { and heart weight } \\
(139.7 \pm 8.3 v s .116 .2 \pm 5.8, p=0.02) \text { in embryo transfer and culture } \\
\text { groups compared to controls. }\end{array}$ & [248] \\
\hline & At birth & $\begin{array}{l}\text { Increased intra-ventricular septum in in vitro produced groups compared to } \\
\text { embryo transfer group (SOF: } 11.8 \pm 0.3 \text {, Co-culture: } 12.0 \pm 0.3 \text {, embryo } \\
\text { transfer } 10 \pm 0.3, p<0.05) \text { Thicker left ventricular wall during diastole in } \\
\text { in vitro produced group (co-culture) when compared to embryo transfer } \\
\text { group }(14.5 \pm 0.5 \text { vs. } 11.8 \pm 0.6, p<0.05) \text {. }\end{array}$ & [249] \\
\hline & 1 year & $\begin{array}{l}\text { Increased relative heart weight in embryo culture group } \\
\qquad(4.01 \pm 0.08 v s .3 .56 \pm 0.12, p<0.02)\end{array}$ & {$[250]$} \\
\hline \multirow{3}{*}{ Rodents } & 21 days after birth & Raised SBP in males. & {$[62]$} \\
\hline & $\begin{array}{l}12-14 \text { weeks } \\
\text { after birth }\end{array}$ & $\begin{array}{l}\text { - Higher mean blood pressure during short-term }(p=0.017) \text { and during } \\
\text { chronic measurements }(p=0.036) \text { in ART mice than in control mice. } \\
\text { - Impaired acetylcholine-induced vasodilation in the mesenteric arteries } \\
\text { in ART mice compared with control mice }(p<0.0001) \text {. } \\
\text { - Increased vascular stiffness in ART mice compared to controls } \\
\text { measured by relationship between inner ( } p=0.017) \text { and outer diameter } \\
\qquad(p=0.033) \text { and carotid pressure in vitro. } \\
\text { - Impaired acetylcholine-induced vasodilation in vitro }(p<0.0001) \text { and } \\
\text { increased mean arterial blood pressure in vivo }(p<0.001) \text { was observed } \\
\text { in the progeny of offspring of ART mate and control female. }\end{array}$ & {$[63,251]$} \\
\hline & 2 years after birth & $\begin{array}{l}\text { Increased heart weight in embryo culture with serum compared to without } \\
\text { serum group }(0.29 \pm 0.02 \text { vs. } 0.20 \pm 0.01, p<0.05) \text {. }\end{array}$ & {$[54]$} \\
\hline
\end{tabular}

SBP, systolic blood pressure.

\subsubsection{Evidence from Ruminants}

Large Offspring Syndrome (LOS) is a serious side effect in culturing of sheep and cow embryos in the presence of serum $[252,253]$ and is associated with an increase in birth weight that persists into 
postnatal life as well as alterations in the relative growth of organs [252,254]. Culturing sheep zygotes in vitro for 5 days in the presence of bovine granulosa cell layers and serum supplementation increased the allometric growth coefficients of key organs, including the heart, from as early as 61 days gestation and this change persisted to 125 days gestation [163]. Interestingly, the allometric growth coefficient of the heart was significantly increased in the fetuses that were cultured in synthetic oviductal fluid media that was supplemented with serum, despite no change in body weight at 61 days gestation. However, by 125 days gestation, the fetuses were significantly heavier with a higher allometric coefficient of the heart [163].

Sheep embryos cultured in synthetic oviductal fluid resulted in fetuses with increased heart weight compared to embryo transfer controls at 125 days gestation [246]. Furthermore, adding serum to synthetic oviductal fluid media during the first $48 \mathrm{~h}$ of embryonic development increased relative heart weight at 125 days gestation, which suggests that inclusion of serum during the precompaction period is more detrimental to the development of the embryo and key organs than the later stages of embryo development [246]. Young et al. found that a loss of methylation of insulin-like growth factor 2 receptor (IGF2R) was associated with the increased heart weight in the embryo culture groups compared to controls [58]. Interestingly, the expression of IGF2R was inversely correlated with heart weight and a stronger inverse relationship existed when the analysis was restricted to the embryo culture groups only, suggesting that IGF2R plays the role of a clearance receptor for IGF2, and thus decreased IGF2R signalling may be responsible for the increase in heart weight because less IGF2 is available to activate the IGF1R signalling pathway leading to cardiac growth [247,255,256].

Similarly, another study also reported an increased heart girth and weight in an embryo transfer and culture group at 222 days of gestation in cows (term, 280 days) [248]. Another study in cows reported an increased intra-ventricular septum in in vitro produced groups (co-culture or synthetic oviductal fluid supplementation) and an increased left ventricular wall during diastole at birth in only the in vitro produced group (co-culture) when compared to the embryo transfer group (term, 280 days) [249]. Few studies have investigated the impact of embryo culture and transfer on the growth and development of the heart in both fetal and postnatal life. However, one study demonstrated that despite normalisation of body weight by 1 year of age, the increase in heart weight persisted in the groups where embryos were cultured in a nutritional media for 5 days after fertilization [250].

\subsubsection{Evidence from Rodents}

In vitro embryo culture during the preimplantation period resulted in increased SBP in both male and female offspring at 21 days after birth [62]. The gene expression of serum angiotensin converting enzyme, which is known to have vasoconstrictive effects through the renin-angiotensin system, was upregulated but only in female offspring [62]. Interestingly, there were no changes in the male offspring, suggesting that an alternative mechanism may be responsible for the increase in SBP [62]. Endothelial dysfunction, higher blood pressure and increased arterial stiffness were found in a mouse model of ART at $12-15$ weeks after birth $[63,251]$. The study also found intergenerational effects of ARTs where the progeny of ART males and control female had endothelial dysfunction and higher mean blood pressure [63,251]. There was also an increase in heart weight in 20 month old mice when the embryos were cultured in media containing fetal calf serum [54]. 


\section{What Are the Most Likely Mechanisms Linking ART and Risk of Cardiovascular Disease in Fetal and Adult Life?}

\subsection{Epigenetic Dysregulation}

Many cardiovascular diseases are known to have an epigenetic origin [179,257]. It has been shown that individuals who were exposed to periconceptional undernutrition such as during the Dutch winter famine 6 decades ago had an altered methylation profile of imprinted and non-imprinted genes and those individuals were also found to have an increased risk of cardiovascular diseases in adulthood [258-260]. In animal studies, epigenetic modifications as well as increased prevalence of many cardiovascular risk factors such as increased blood pressure, adiposity and insulin resistance were found in the offspring exposed to nutritional manipulations during the periconceptional period $[59,261]$. These findings suggest that epigenetic dysregulation could be a plausible mechanism that links ARTs with increased risk factors for cardiovascular diseases [262].

A series of studies have identified an association between ARTs and epigenetic disorders [95,263]. Children with Beckwith-Wiedemann syndrome, which is caused by an imprinting disorder, are 3-14 times more likely to be conceived by ARTs [264-267]. Molecular analysis in these studies showed hypomethylation of maternal copy of KCNQ1 overlapping transcript 1 (KCNQ1OTI), an antisense RNA normally expressed from the paternal allele and located at one of the differentially methylated regions (DMRs) of chromosome 11p15 [264-269]. Studies have also found hypermethylation of HI9, which is located at another DMR of chromosome 11p15, as well as hypomethylation of mesoderm-specific transcript homolog protein (MEST), small nuclear ribonucleoprotein N (SNPRN), pleiomorphic adenoma gene-like 1 (PLAGL1) in ART children with Beckwith-Wiedemann syndrome [264,268,269]. There are also reports of other imprinting defects such as Angelman syndrome, Retinoblastoma, Prader-Willi syndrome and Russell-Silver syndrome in children conceived through ARTs [270,271]. At the blastocyst stage, IVF resulted in aberrant H19 methylation in humans and mice [226,272]. Large offspring syndrome LOS is a frequent occurrence in livestock conceived through ARTs and is also caused by loss of methylation in the maternal DMR of IGF2R, which is an imprinted gene [58].

A study investigating the DNA methylation levels of more than 700 genes (1536 CpG sites) in the placenta and cord blood reported lower mean methylation at $\mathrm{CpG}$ sites in the placenta and higher mean methylation at $\mathrm{CpG}$ sites in cord blood from 10 children conceived in vitro compared to 13 children conceived naturally. Upon examining the gene expression levels of a subset of genes that had altered methylation levels, CCAAT/enhancer-binding protein alpha (CEBPA) in cord blood and CEBPA, MEST, neuronatin (NNAT) and serpin peptidase inhibitor, clade F (alpha-2 antiplasmin, pigment epithelium derived factor), member 1(SERPINF1) in placenta had significant difference in mean transcript levels [273]. Interestingly these genes are known to be associated with adipocyte development and differentiation, insulin signalling and/or obesity [274-277].

Increased methylation of the imprinted genes H19, glucosyltransferase 2 (GTL2) and decreased methylation of paternally-expressed gene 3 (PEG3) were found in the aorta, but not in the liver of the mice conceived through ART [251]. This alteration of the methylation levels was transmitted to the next generation with levels comparable to the methylation of the parent generation [251]. Interestingly, the altered methylation levels were restored in ART mice and in its progeny with the administration of 
butyrate (a histone deacetylase inhibitor) [251]. As previously mentioned, the study also found vascular dysfunction and arterial hypertension in ARTs mice and its offspring. Consistent with this finding, the study reported an increased DNA methylation of the promoter of the eNOS gene in the aorta of the ARTs mice, which is an important regulator for systemic vascular function [251]. This increased methylation level resulted in decreased eNOS mRNA expression in the vasculature and lower levels of nitric oxide in the plasma of ARTs mice [251]. In addition, butyrate administration to ARTs mice also normalized DNA methylation of the promoter of the eNOS gene, eNOS mRNA expression and plasma nitric oxide concentration [251].

These altered methylation levels provide strong evidence for epigenetic dysregulation as a result of ARTs, which could possibly affect the expression levels of genes involved in cardiovascular regulation as well as other major regulatory pathways increasing the risk of long-term diseases in adult life [63]. These alterations in epigenetic mechanisms may stem from several steps involved in ARTs such as ovarian stimulations and in vitro embryo culture (Figure 3). Studies have investigated the impact of these steps separately, which may underpin the source for epigenetic dysregulations $[163,278,279]$.

\subsubsection{Ovarian Hyperstimulation/Superovulation}

Superovulation occurs during meiosis of oocyte development/maturation when the oocytes are still acquiring imprinting marks and may lead to imprinting defects. In humans, studies have reported hypomethylation of the KCNQ1OT1 DMR (KvDMR1) in the germinal vesicle and metaphase I stage as well as hypomethylation of KCNQ1OT1 in the metaphase II stage of the superovulated oocytes, which suggests that ovarian hyperstimulation may result in the release of immature or young oocytes that have not undergone complete methylation, including the establishment of appropriate imprinting [85,280]. Imprinting errors have been found in H19 and MEST in metaphase II oocytes after ovarian stimulation, however, it could not be determined whether alterations in the methylation patterns of these genes were associated with the superovulation process itself or the age and infertility status of the patients [281]. There is evidence that superovulation can affect the quality of the embryo as well as the uterine milieu, and these factors can indirectly affect the epigenetic status of the oocyte [48].

In animal studies where infertility is not a confounding factor, an abnormal methylation pattern at the 2 cell stage was found in the embryos from superovulated mice using immunofluorescent staining [282]. Downregulation of candidate reprogramming genes which are involved in base excision repair proteins such as APEX nuclease (multifunctional DNA repair enzyme) 1 (APEX1), polymerase (DNA directed), beta (POLB) and the 5-methyl-CpG were found at the morula stage of the mouse embryo after superovulation and suggests that superovulation may also hamper the maintenance of imprinting [278]. In line with this finding, lower protein expression levels of APEXI were observed in both early and late morula stages and the level of protein expression correlated the mRNA expression levels [278]. Loss of methylation of SNRPN, KCNQ1OT1 and PEG3 in the blastocyst stage was also observed in a dose-dependent manner with higher doses of hormones resulting in greater imprinting disturbances [283]. Superovulation in mice decreased the methylation levels of $\mathrm{H} 19$ and significantly increased the methylation levels of PEG1 and SNRPN imprinted genes in the sperm of the offspring in both the first and second generation [53]. Together these data suggest that changes in global methylation may account for spontaneous embryo loss and developmental failure, while locus-specific epigenetic errors may result in 
defined phenotypes associated with genomic imprinting disorders; thereby suggesting that oocytes from superovulated animals may have a reduced ability to complete the global reprogramming necessary for proper development [282,284].

\subsubsection{In Vitro Embryo Culture}

In vitro embryo culture occurs during the sensitive period of maternal and paternal demethylation and remethylation and thus may affect the maintenance of genomic imprinting during this process [285]. There is evidence of abnormal methylation, mainly due to embryo culture, as a result of the IVF procedure in mice [286]. For example, embryo culture of preimplantation mouse embryos using Whitten medium resulted in biallelic expression and loss of methylation of the $\mathrm{H} 19$ gene [287]. Similarly a greater loss of methylation was observed in H19 after embryo culture in M16 medium than in G1/G2 medium [287]. There were also differences in the gene expression of 114 genes in the preimplantation embryos of the mice cultured in Whitten culture medium and 29 genes when cultured in KSOM + AA [61]. Biallelic expression of the imprinted gene $\mathrm{H} 19$ was found in the placenta which persisted till mid gestation when the embryos were cultured in whitten or KSOM + AA medium [288]. There is also evidence of perturbed gene expression after embryo culture [163]. Increased expression of the imprinted genes, IGF2 and H19 and growth factor receptor binding protein 10 (GRB10), along with increased methylation of H19 and decreased methylation of growth factor receptor binding protein 7 (GRB7) were observed in fetuses that had undergone preimplantation embryo culture in M16 medium with fetal calf serum supplementation [61]. In vitro culture with serum supplementation also resulted in hypomethylation of IGF2R associated with LOS in ruminants [58]. It has been speculated that culture media procedures may induce abnormal methylation at imprinted loci by facilitation the removal of methyl groups from cytosine bases or interfering in normal gamete development which may lead to incomplete imprint erasure and/or reestablishment of methylation pattern [95,285]. The methionine content of the media may also affect DNA methylation and imprinting [102,289].

These findings provide substantial evidence that in vitro embryo culture can impair epigenetic mechanisms. Studies investigating epigenetic dysregulation associated with both ovarian stimulation and embryo culture found that defects in imprinting were neither observed in all the embryos nor at every imprinting locus. Some loci were affected more than others. Hence, more studies are required to understand the stochastic nature of these imprinting defects.

\subsection{Impaired Gastrulation}

Early interaction between the embryo and the endometrium is critical for proper development and implantation of the embryo [290,291]. This in turn determines proper gastrulation and organogenesis. Embryo cultured in media in vitro lacks these early interactions and the exchange of factors between embryo and endometrium. This can alter the timing of expression of Hox genes, which control the body plan of an embryo along the anterior-posterior (head-tail) axis [292,293]. In addition, studies have shown that culture of the embryo in vitro affects the proper differentiation of the inner cell mass, which are precursors of ectoderm and endoderm (germ layers formed during gastrulation) [294,295]. These two, individually or in combination, can alter gastrulation and subsequently organogenesis. It is reasonable to speculate that organogenesis of the heart, which is the first organ to form, may be affected by procedures 
involved in ARTs and abnormalities in heart development are known to cause congenital defects and other cardiovascular disorders (Figure 3) [296].

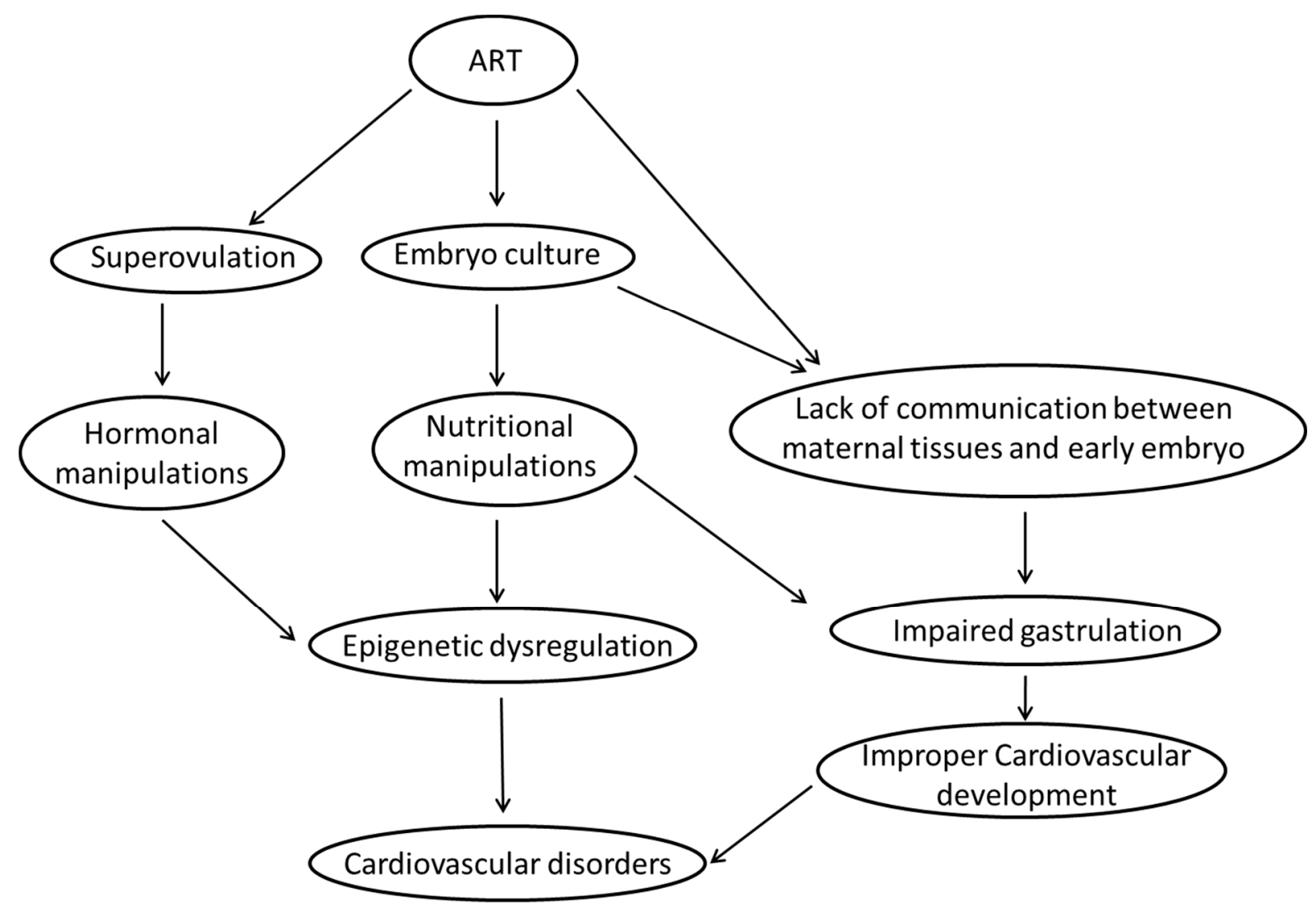

Figure 3. Diagrammatic representation of the possible links between ARTs and cardiovascular disorders [284,293,297]

\section{Conclusions}

This review summarises the literature showing that ARTs are associated with an increased risk of cardiovascular disease. Many studies have been conducted that have shown an association between ARTs and congenital heart defects. It is clear from the available evidence that the association is not restricted to a specific type of ARTs. However, a major gap of literature exists in terms of our understanding of the long-term effects of ARTs in childhood and adulthood. Some follow-up studies have confirmed these findings in children of ARTs in the fetal and neonatal periods. Given the young age of the ART population, it is necessary to perform life course studies that will provide valuable evidence not only to ensure better medical diagnostics and care for these children but also to call for more studies to pinpoint the mechanistic alterations that are responsible for ARTs induced cardiovascular risk factors. Understanding the important events that occur during the developmental periods when ARTs procedures are applied have identified mechanisms underlying the link between ART and an increased risk of cardiovascular defects in the embryonic period and cardiovascular disease in postnatal life.

Epigenetic alterations have emerged as a key mechanistic alteration that can predispose an increased risk of cardiovascular disorders in the ART population. A major challenge is to isolate the effects of infertility of the parents that sought ARTs procedures and may render epigenetic alterations in the offspring. 
In this regard, many animal models of ARTs have been a major source of evidence suggesting the effects of ARTs procedures on cardiovascular dysfunctions and epigenetic alterations. This warrants further studies to pinpoint specific epigenetic alterations that directly link to the development of cardiovascular disease in later life. Consequently, a genome-wide epigenetic profiling of children conceived through ARTs during the embryonic stages can be used as a tool to identify embryos that carry epigenetic alterations linked to the development of cardiovascular disease in adult life. Furthermore, epigenetic profiling can also be conducted in both neonatal and adult life, to identify individuals with a higher risk of developing cardiovascular disease in later life.

\section{Acknowledgments}

J.L.M. was funded by a South Australian Cardiovascular Research Network Fellowship (CR10A4988) and a NHMRC Career Development Fellowship (APP1066916).

\section{Conflicts of Interest}

The authors declare no conflict of interest.

\section{References}

1. Jurema, M.W.; Nogueira, D. In vitro maturation of human oocytes for assisted reproduction. Fertil. Steril. 2006, 86, 1277-1291.

2. Fleming, T.P.; Kwong, W.Y.; Porter, R.; Ursell, E.; Fesenko, I.; Wilkins, A.; Miller, D.J.; Watkins, A.J.; Eckert, J.J. The embryo and its future. Biol. Reprod. 2004, 71, 1046-1054.

3. Louis, G.M.B.; Cooney, M.A.; Lynch, C.D.; Handal, A. Periconception window: Advising the pregnancy-planning couple. Fertil. Steril. 2008, 89, e119-e121.

4. Czeizel, A.E. Prevention of congenital abnormalities by periconceptional multivitamin supplementation. BMJ 1993, 306, 1645-1648.

5. Van Uitert, E.M.; van der Elst-Otte, N.; Wilbers, J.J.; Exalto, N.; Willemsen, S.P.; Eilers, P.H.C.; Koning, A.H.J.; Steegers, E.A.P.; Steegers-Theunissen, R.P.M. Periconception maternal characteristics and embryonic growth trajectories: The Rotterdam Predict Study. Hum. Reprod. 2013, 28, 3188-3196.

6. Schelbach, C.J.; Robker, R.L.; Bennett, B.D.; Gauld, A.D.; Thompson, J.G.; Kind, K.L. Altered pregnancy outcomes in mice following treatment with the hyperglycaemia mimetic, glucosamine, during the periconception period. Reprod. Fertil. Dev. 2013, 25, 405-416.

7. Watkins, A.J.; Lucas, E.S.; Wilkins, A.; Cagampang, F.R.A.; Fleming, T.P. Maternal periconceptional and gestational low protein diet affects mouse offspring growth, cardiovascular and adipose phenotype at 1 year of age. PLoS One 2011, 6, e28745.

8. Maloney, C.A.; Hay, S.M.; Reid, M.D.; Duncan, G.; Nicol, F.; Sinclair, K.D.; Rees, W.D. A methyl-deficient diet fed to rats during the pre- and peri-conception periods of development modifies the hepatic proteome in the adult offspring. Genes Nutr. 2013, 8, 181-190. 
9. Kwong, W.Y.; Miller, D.J.; Ursell, E.; Wild, A.E.; Wilkins, A.P.; Osmond, C.; Anthony, F.W.; Fleming, T.P. Imprinted gene expression in the rat embryo-fetal axis is altered in response to periconceptional maternal low protein diet. Reproduction 2006, 132, 265-277.

10. Bloomfield, F.H. Periconceptional undernutrition in sheep accelerates maturation of the fetal hypothalamic-pituitary-adrenal axis in late gestation. Endocrinology 2004, 145, 4278-4278.

11. Oliver, M.H.; Hawkins, P.; Harding, J.E. Periconceptional undernutrition alters growth trajectory and metabolic and endocrine responses to fasting in late-gestation fetal sheep. Pediatr. Res. 2005, 57, 591-598.

12. Spencer, T.E.; Johnson, G.A.; Bazer, F.W.; Burghardt, R.C. Implantation mechanisms: Insights from the sheep. Reproduction 2004, 128, 657-668.

13. Gardner, D.S.; van Bon, B.W.M.; Dandrea, J.; Goddard, P.J.; May, S.F.; Wilson, V.; Stephenson, T.; Symonds, M.E. Effect of periconceptional undernutrition and gender on hypothalamicpituitary-adrenal axis function in young adult sheep. J. Endocrinol. 2006, 190, 203-212.

14. Bazer, F.W.; Wu, G.; Johnson, G.A.; Kim, J.; Song, G. Uterine histotroph and conceptus development: select nutrients and secreted phosphoprotein 1 affect mechanistic target of rapamycin cell signaling in ewes. Biol. Reprod. 2011, 85, 1094-1107.

15. Zhang, S.; Rattanatray, L.; Morrison, J.L.; Nicholas, L.M.; Lie, S.; McMillen, I.C. Maternal obesity and the early origins of childhood obesity: Weighing up the benefits and costs of maternal weight loss in the periconceptional period for the offspring. Exp. Diabetes Res. 2011, 2011, 10.

16. Edwards, L.J.; McFarlane, J.R.; Kauter, K.G.; McMillen, I.C. Impact of periconceptional nutrition on maternal and fetal leptin and fetal adiposity in singleton and twin pregnancies. Am. J. Physiol. Regul. Integr. Comp. Physiol. 2005, 288, R39-45.

17. Torrens, C.; Snelling, T.H.; Chau, R.; Shanmuganathan, M.; Cleal, J.K.; Poore, K.R.; Noakes, D.E.; Poston, L.; Hanson, M.A.; Green, L.R. Effects of pre- and periconceptional undernutrition on arterial function in adult female sheep are vascular bed dependent. Exp. Physiol. 2009, 94, 1024-1033.

18. Edwards, L.J.; McMillen, I.C. Impact of maternal undernutrition during the periconceptional period, fetal number, and fetal sex on the development of the hypothalamo-pituitary adrenal axis in sheep during late gestation. Biol. Reprod. 2002, 66, 1562-1569.

19. MacLaughlin, S.M.; Mühlhäusler, B.S.; Gentili, S.; McMillen, I.C. When in gestation do nutritional alterations exert their effects? A focus on the early origins of adult disease. Curr. Opin. Endocrinol. Diabetes Obes. 2006, 13, 516-522.

20. McMillen, I.C.; MacLaughlin, S.M.; Muhlhausler, B.S.; Gentili, S.; Duffield, J.L.; Morrison, J.L. Developmental origins of adult health and disease: The role of periconceptional and foetal nutrition. Basic Clin. Pharmacol. Toxicol. 2008, 102, 82-89.

21. Bachvarova, R. Gene expression during oogenesis and oocyte development in mammals. In Oogenesis; Browder, L., Ed.; Springer US: New York, NY, USA, 1985; Volume 1, pp. 453-524.

22. Eddy, E.; Clark, J.M.; Gong, D.; Fenderson, B.A. Origin and migration of primordial germ cells in mammals. Gamete Res. 1981, 4, 333-362.

23. Schoenwolf, G.C., Bleyl, S.; Brauer, P.R.; Francis-West, P.H. Larsen's Human Embryology; Churchill Livingstone/Elsevier Philadelphia: Philadelphia, PA, USA, 2009. 
24. Carlson, B.M. Human Embryology and Developmental Biology; Elsevier Health Sciences: Philadelphia, PA, USA, 2013.

25. Wilcox, A.J. Fertility and Pregnancy: An Epidemiologic Perspective: An Epidemiologic Perspective; Oxford University Press: USA: New York, NY, USA, 2010.

26. Gougeon, A. Regulation of ovarian follicular development in primates: Facts and hypotheses. Endocr. Rev. 1996, 17, 121-155.

27. Bernal, A.B.; Vickers, M.H.; Hampton, M.B.; Poynton, R.A.; Sloboda, D.M. Maternal undernutrition significantly impacts ovarian follicle number and increases ovarian oxidative stress in adult rat offspring. PLoS One 2010, 5, e15558.

28. Connor, K.L.; Vickers, M.H.; Beltrand, J.; Meaney, M.J.; Sloboda, D.M. Nature, nurture or nutrition? Impact of maternal nutrition on maternal care, offspring development and reproductive function. J. Physiol. 2012, 590, 2167-2180.

29. Sloboda, D.M.; Hickey, M.; Hart, R. Reproduction in females: The role of the early life environment. Hum. Reprod. Update 2011, 17, 210-227.

30. Guzmán, C.; Cabrera, R.; Cárdenas, M.; Larrea, F.; Nathanielsz, P.W.; Zambrano, E. Protein restriction during fetal and neonatal development in the rat alters reproductive function and accelerates reproductive ageing in female progeny. J. Physiol. 2006, 572, 97-108.

31. Intapad, S.; Alexander, B.T. The double hit of growth restriction: Its origins and outcome on this generation and the next. J. Physiol. 2012, 590, 1019-1019.

32. Gallo, L.A.; Tran, M.; Moritz, K.M.; Jefferies, A.J.; Wlodek, M.E. Pregnancy in aged rats that were born small: Cardiorenal and metabolic adaptations and second-generation fetal growth. FASEB J. 2012, 26, 4337-4347.

33. Torrens, C.; Poston, L.; Hanson, M.A. Transmission of raised blood pressure and endothelial dysfunction to the $\mathrm{F} 2$ generation induced by maternal protein restriction in the $\mathrm{F} 0$, in the absence of dietary challenge in the F1 generation. Br. J. Nutr. 2008, 100, 760-766.

34. Benyshek, D.C.; Johnston, C.S.; Martin, J.F.; Ross, W.D. Insulin sensitivity is normalized in the third generation (F3) offspring of developmentally programmed insulin resistant (F2) rats fed an energy-restricted diet. Nutr. Metab. (Lond.) 2008, 5, 26.

35. Kott, R. Montana farm flock sheep production handbook. In Animal \& Range Sciences, Extension Service; Montana State University: Bozeman, MT, USA, 2006.

36. Wilcox, A.J.; Dunson, D.; Baird, D.D. The timing of the "fertile window" in the menstrual cycle: Day specific estimates from a prospective study. BMJ 2000, 321, 1259-1262.

37. Long, J.A.; Evans, H.M. The Oestrous Cycle in the Rat and Its Associated Phenomena; University of California Press: Berkeley, CA, USA, 1922; Volume 6.

38. Allen, E. The oestrous cycle in the mouse. Am. J. Anat. 1922, 30, 297-371.

39. Fortune, J.E. Ovarian follicular growth and development in mammals. Biol. Reprod. 1994, 50, $225-232$.

40. Hirshfield, A.N. Development of follicles in the mammalian ovary. Int. Rev. Cytol. 1991, 124, 43-101.

41. McGee, E.A.; Hsueh, A.J. Initial and cyclic recruitment of ovarian follicles. Endocr. Rev. 2000, 21, 200-214.

42. Wassarman, P.M. Zona Pellucida Glycoproteins. Annu. Rev. Biochem. 1988, 57, 415-442. 
43. Hennet, M.L.; Combelles, C.M. The antral follicle: A microenvironment for oocyte differentiation. Int. J. Dev. Biol. 2012, 56, 819-831.

44. Rodgers, R.J.; Irving-Rodgers, H.F. Formation of the ovarian follicular antrum and follicular fluid. Biol. Reprod. 2010, 82, 1021-1029.

45. Hill, M.A. Embryology Fertilization. Available online: https://php.med.unsw.edu.au/embryology/ index.php?title=Fertilization (accessed on 18 November 2014).

46. Senger, P.L. Pathways to Pregnancy and Parturition; 1st ed.; Current Conceptions, Inc.: Pullman, WA, USA, 1999; pp. 206-246.

47. Krisher, R.L. The effect of oocyte quality on development. J. Anim. Sci. 2004, 82, E14-E23.

48. Ertzeid, G.; Storeng, R. The impact of ovarian stimulation on implantation and fetal development in mice. Hum. Reprod. 2001, 16, 221-225.

49. Van der Auwera, I.; D'Hooghe, T. Superovulation of female mice delays embryonic and fetal development. Hum. Reprod. 2001, 16, 1237-1243.

50. Kelley-Quon, L.I.; Tseng, C.-H.; Janzen, C.; Shew, S.B. Congenital malformations associated with assisted reproductive technology: A California statewide analysis. J. Pediatr. Surg. 2013, 48, 1218-1224.

51. Ceelen, M.; van Weissenbruch, M.M.; Vermeiden, J.P. W.; van Leeuwen, F.E.; Delemarre-van de Waal, H.A. Growth and development of children born after in vitro fertilization. Fertil. Steril. 2008, 90, 1662-1673.

52. Sutcliffe, A.G.; Ludwig, M. Outcome of assisted reproduction. Lancet 2007, 370, 351-359.

53. Stouder, C.; Deutsch, S.; Paoloni-Giacobino, A. Superovulation in mice alters the methylation pattern of imprinted genes in the sperm of the offspring. Reprod. Toxicol. 2009, 28, 536-541.

54. Fernández-Gonzalez, R.; Moreira, P.; Bilbao, A.; Jiménez, A.; Pérez-Crespo, M.; Ramírez, M.A.; de Fonseca, F.R.; Pintado, B.; Gutiérrez-Adán, A. Long-term effect of in vitro culture of mouse embryos with serum on mRNA expression of imprinting genes, development, and behavior. Proc. Natl. Acad. Sci. USA 2004, 101, 5880-5885.

55. Mainigi, M.A.; Olalere, D.; Burd, I.; Sapienza, C.; Bartolomei, M.; Coutifaris, C. Peri-implantation hormonal milieu: Elucidating mechanisms of abnormal placentation and fetal growth. Biol. Reprod. 2014, 90, 26.

56. Fauque, P.; Mondon, F.; Letourneur, F.; Ripoche, M.-A.; Journot, L.; Barbaux, S.; Dandolo, L.; Patrat, C.; Wolf, J.-P.; Jouannet, P.; et al. In vitro fertilization and embryo culture strongly impact the placental transcriptome in the mouse model. PLoS One 2010, 5, e9218.

57. Alikani, M.; Calderon, G.; Tomkin, G.; Garrisi, J.; Kokot, M.; Cohen, J. Cleavage anomalies in early human embryos and survival after prolonged culture in vitro. Hum. Reprod. 2000, 15, 2634-2643.

58. Young, L.E.; Fernandes, K.; McEvoy, T.G.; Butterwith, S.C.; Gutierrez, C.G.; Carolan, C.; Broadbent, P.J.; Robinson, J.J.; Wilmut, I.; Sinclair, K.D. Epigenetic change in IGF2R is associated with fetal overgrowth after sheep embryo culture. Nat. Genet. 2001, 27, 153-154.

59. Watkins, A.J.; Fleming, T.P. Blastocyst environment and its influence on offspring cardiovascular health: The heart of the matter. J. Anat. 2009, 215, 52-59. 
60. McEvoy, T.G.; Sinclair, K.D.; Young, L.E.; Wilmut, I.; Robinson, J.J. Large offspring syndrome and other consequences of ruminant embryo culture in vitro: Relevance to blastocyst culture in human ART. Hum. Fertil. 2000, 3, 238-246.

61. Khosla, S.; Dean, W.; Brown, D.; Reik, W.; Feil, R. Culture of preimplantation mouse embryos affects fetal development and the expression of imprinted genes. Biol. Reprod. 2001, 64, 918-926.

62. Watkins, A.J.; Platt, D.; Papenbrock, T.; Wilkins, A.; Eckert, J.J.; Kwong, W.Y.; Osmond, C.; Hanson, M.; Fleming, T.P. Mouse embryo culture induces changes in postnatal phenotype including raised systolic blood pressure. Proc. Natl. Acad. Sci. USA 2007, 104, 5449-5454.

63. Rimoldi, S.F.; Sartori, C.; Rexhaj, E.; Cerny, D.; Von Arx, R.; Soria, R.; Germond, M.; Allemann, Y.; Scherrer, U. Vascular dysfunction in children conceived by assisted reproductive technologies: Underlying mechanisms and future implications. Swiss Med. Wkly. 2014, 144, w13973.

64. Valbuena, D.; Jasper, M.; Remohí, J.; Pellicer, A.; Simón, C. Ovarian stimulation and endometrial receptivity. Hum. Reprod. 1999, 14, 107-111.

65. Ruiz-Alonso, M.; Blesa, D.; Simón, C. The genomics of the human endometrium. Biochim. Biophys. Acta-Mol. Basis Dis. 2012, 1822, 1931-1942.

66. Rahman, A.; Abdullah, R.; Wan-Khadijah, W. Gametogenesis, fertilization and early embryogenesis in mammals with special reference to goat: A review. J. Biol. Sci. 2008, 8, 1115-1128.

67. Ecochard, R.; Gougeon, A. Side of ovulation and cycle characteristics in normally fertile women. Hum. Reprod. 2000, 15, 752-755.

68. Minami, N.; Suzuki, T.; Tsukamoto, S. Zygotic Gene Activation and Maternal Factors in Mammals. J. Reprod. Dev. 2007, 53, 707-715.

69. Zernicka-Goetz, M. Activation of embryonic genes during preimplantation rat development. Mol. Reprod. Dev. 1994, 38, 30-35.

70. Young, W.C.; Boling, J.L.; Blandau, R.J. The vaginal smear picture, sexual receptivity and time of ovulation in the albino rat. Anat. Rec. 1941, 80, 37-45.

71. Green, E.L. Biology of the laboratory mouse. Dover Publications Inc.: New York, NY, USA, 1966.

72. Hill, M.A. Embryology Rat Development. Available online: https://php.med.unsw.edu.au/ embryology/index.php?title=Rat_Development (accessed on 20 November 2014).

73. Hill, M.A. Embryology Mouse Development. Available online: https://php.med.unsw.edu.au/ embryology/index.php?title=Mouse_Development (accessed on 20 November 2014).

74. Spencer, T.E.; Johnson, G.A.; Bazer, F.W.; Burghardt, R.C.; Palmarini, M. Pregnancy recognition and conceptus implantation in domestic ruminants: Roles of progesterone, interferons and endogenous retroviruses. Reprod. Fertil. Dev. 2006, 19, 65-78.

75. Schultz, R.M. The molecular foundations of the maternal to zygotic transition in the preimplantation embryo. Hum. Reprod. Update 2002, 8, 323-331.

76. Schultz, R.M. Regulation of zygotic gene activation in the mouse. Bioessays 1993, 15, 531-538.

77. Li, L.; Lu, X.; Dean, J. The Maternal to Zygotic Transition in Mammals. Mol. Asp. Med. 2013, 34, 919-938.

78. Kafri, T.; Ariel, M.; Brandeis, M.; Shemer, R.; Urven, L.; McCarrey, J.; Cedar, H.; Razin, A. Developmental pattern of gene-specific DNA methylation in the mouse embryo and germ line. Genes Dev. 1992, 6, 705-714. 
79. Stojanov, T.; O’Neill, C. Ontogeny of expression of a receptor for platelet-activating factor in mouse preimplantation embryos and the effects of fertilization and culture in vitro on its expression. Biol. Reprod. 1999, 60, 674-682.

80. Stojanov, T.; O'Neill, C. In vitro fertilization causes epigenetic modifications to the onset of gene expression from the zygotic genome in mice. Biol. Reprod. 2001, 64, 696-705.

81. Van Voorhis, B.J. In vitro fertilization. N. Engl. J. Med. 2007, 356, 379-386.

82. Abyholm, T.; Tanbo, T. GIFT, ZIFT, and related techniques. Curr. Opin. Obstet. Gynecol. 1993, 5, 615-622.

83. Sutherland, J.E.; Costa, M.A.X. Epigenetics and the environment. Ann. N. Y. Acad. Sci. 2003, 983, 151-160.

84. Egger, G.; Liang, G.; Aparicio, A.; Jones, P.A. Epigenetics in human disease and prospects for epigenetic therapy. Nature 2004, 429, 457-463.

85. Tchurikov, N.A. Molecular mechanisms of epigenetics. Biochemistry (Moscow) 2005, 70, 406-423.

86. Gu, L.; Wang, Q.; Sun, Q.Y. Histone modifications during mammalian oocyte maturation: Dynamics, regulation and functions. Cell Cycle 2010, 9, 1942-1950.

87. Reik, W.; Dean, W.; Walter, J. Epigenetic reprogramming in mammalian development. Science 2001, 293, 1089-1093.

88. Morgan, H.D.; Santos, F.; Green, K.; Dean, W.; Reik, W. Epigenetic reprogramming in mammals. Hum. Mol. Genet. 2005, 14, R47-R58.

89. Santos, F.; Dean, W. Epigenetic reprogramming during early development in mammals. Reproduction 2004, 127, 643-651.

90. Mayer, W.; Niveleau, A.; Walter, J.; Fundele, R.; Haaf, T. Embryogenesis: Demethylation of the zygotic paternal genome. Nature 2000, 403, 501-502.

91. Allegrucci, C.; Thurston, A.; Lucas, E.; Young, L. Epigenetics and the germline. Reproduction 2005, 129, 137-149.

92. Li, E.; Beard, C.; Jaenisch, R. Role for DNA methylation in genomic imprinting. Nature 1993, $366,362-365$.

93. Reik, W.; Walter, J. Genomic imprinting: Parental influence on the genome. Nat. Rev. Genet. 2001, 2, 21-32.

94. Rodriguez-Osorio, N.; Dogan, S.; Memili, E. Epigenetics of mammalian gamete and embryo development. In Livestock Epigenetics; 1st ed.; Hassan, K.; Ed.; Wiley-Blackwell: Oxford, UK, 2011; pp. 3-25.

95. De Rycke, M.; Liebaers, I.; van Steirteghem, A. Epigenetic risks related to assisted reproductive technologies: Risk analysis and epigenetic inheritance. Hum. Reprod. 2002, 17, 2487-2494.

96. Reik, W.; Constância, M.; Fowden, A.; Anderson, N.; Dean, W.; Ferguson-Smith, A.; Tycko, B.; Sibley, C. Regulation of supply and demand for maternal nutrients in mammals by imprinted genes. J. Physiol. 2003, 547, 35-44.

97. Lambertini, L.; Marsit, C.J.; Sharma, P.; Maccani, M.; Ma, Y.; Hu, J.; Chen, J. Imprinted gene expression in fetal growth and development. Placenta 2012, 33, 480-486.

98. Abu-Amero, S.; Monk, D.; Apostolidou, S.; Stanier, P.; Moore, G. Imprinted genes and their role in human fetal growth. Cytogenet. Genome Res. 2006, 113, 262-270. 
99. Hall, J.G. Genomic imprinting: Review and relevance to human diseases. Am. J. Hum. Genet. 1990, $46,857-873$.

100. Amor, D.J.; Halliday, J. A review of known imprinting syndromes and their association with assisted reproduction technologies. Hum. Reprod. 2008, 23, 2826-2834.

101. Dominguez-Salas, P.; Moore, S.E.; Baker, M.S.; Bergen, A.W.; Cox, S.E.; Dyer, R.A.; Fulford, A.J.; Guan, Y.; Laritsky, E.; Silver, M.J.; et al. Maternal nutrition at conception modulates DNA methylation of human metastable epialleles. Nat. Commun. 2014, 5, doi:10.1038/ncomms4746.

102. Niemitz, E.L.; Feinberg, A.P. Epigenetics and assisted reproductive technology: A call for investigation. Am. J. Hum. Genet. 2004, 74, 599-609.

103. Schieve, L.A.; Meikle, S.F.; Ferre, C.; Peterson, H.B.; Jeng, G.; Wilcox, L.S. Low and very low birth weight in infants conceived with use of assisted reproductive technology. N. Engl. J. Med. 2002, 346, 731-737.

104. Zegers-Hochschild, F.; Adamson, G.D.; de Mouzon, J.; Ishihara, O.; Mansour, R.; Nygren, K.; Sullivan, E.; van der Poel, S. The International Committee for Monitoring Assisted Reproductive Technology (ICMART) and the World Health Organization (WHO) revised glossary on ART terminology, 2009. Hum. Reprod. 2009, 24, 2683-2687.

105. Heape, W. Preliminary note on the transplantation and grwoth of mammalian ova within a uterine foster mother. Proc. R. Soc. 1890, 48, 457-458.

106. Betteridge, K.J. Reflections on the golden anniversary of the first embryo transfer to produce a calf. Theriogenology 2000, 53, 3-10.

107. De Kretzer, D.; Dennis, P.; Hudson, B.; Leeton, J.; Lopata, A.; Outch, K.; Talbot, J.; Wood, C. Transfer of a human zygote. Lancet 1973, 302, 728-729.

108. Steptoe, P.C.; Edwards, R.G. Birth after the reimplantation of a human embryo. Lancet 1978, 312, 366-366.

109. Kamel, R.M. Assisted reproductive technology after the birth of louise brown. J. Reprod. Infertil. 2013, 14, 96-109.

110. ART Fact Sheet. Available online: http://www.eshre.eu/sitecore/content/Home/Guidelines\%20 and\%20Legal/ART\%20fact\%20sheet (accessed on 16 November 2014).

111. Balasch, J. Investigation of the infertile couple: Investigation of the infertile couple in the era of assisted reproductive technology: A time for reappraisal. Hum. Reprod. 2000, 15, 2251-2257.

112. Wyndham, N.; Marin Figueira, P.G.; Patrizio, P. A persistent misperception: Assisted reproductive technology can reverse the "aged biological clock". Fertil. Steril. 2012, 97, 1044-1047.

113. Hilder, L.; Zhichao, Z.; Parker, M., Jahan, S., Chambers G.M. Australia's mothers and babies 2012; Perinatal statistics series no. 30. Cat. no. PER 69. Australian Institute of Health and Welfare and University: Canberra, Australia, 2014.

114. Nash, M. Making 'Postmodern' Mothers: Pregnant Embodiment, Baby Bumps and Body Image. Palgrave Macmillan: England, UK, 2012.

115. Australian Institute of Family Studies. Available online: http://www.aifs.gov.au/institute/ info/charts/births/\#age (accessed on 16 November 2014). 
116. Martin, J.A.; Hamilton, B.E.; Osterman, M.J.K.; Curtin, S.C.; Mathews, T.J. Births: Final Data for 2012; National Vital Statistics Reports, Vol 62 No 9; National Center for Health Statistics: Hyattsville, MD, USA, 30 December 2013.

117. Millan, A. Fertility: Overview, 2008; Report on the Demographic Situation in Canada, Catalogue no. 91-209-X.; Authority of the Minister responsible for Statistics Canada: Ottawa, Canada, August 2011.

118. Dunson, D.B.; Colombo, B.; Baird, D.D. Changes with age in the level and duration of fertility in the menstrual cycle. Hum. Reprod. 2002, 17, 1399-1403.

119. Van Noord-Zaadstra, B.M.; Looman, C.W.; Alsbach, H.; Habbema, J.D.; te Velde, E.R.; Karbaat, J. Delaying childbearing: Effect of age on fecundity and outcome of pregnancy. BMJ 1991, 302, 1361.

120. Hassan, M.A.; Killick, S.R. Effect of male age on fertility: Evidence for the decline in male fertility with increasing age. Fertil. Steril. 2003, 79, 1520-1527.

121. Leridon, H. Can assisted reproduction technology compensate for the natural decline in fertility with age? A model assessment. Hum. Reprod. 2004, 19, 1548-1553.

122. Macaldowie, A.; Wang, Y.A.; Chambers, G.M.; Sullivan, E.A. Assisted Reproductive Technology in Australia and New Zealand 2012; AIHW: Canberra, Australia, 2012.

123. Moore, K.; Thatcher, W.W. Major advances associated with reproduction in dairy cattle. J. Dairy Sci. 2006, 89, 1254-1266.

124. Sejian, V.; Meenambigai, T.V.; Chandirasegaran, M.; Naqvi, S.M.K. reproductive technology in farm animals: New facets and findings: A review. J. Biol. Sci. 2010, 10, 686-700.

125. Chakravarthi, P.; Balaji, N. Use of assisted reproductive technologies for livestock development. Vet. World 2010, 3, 238-240.

126. Amiridis, G.S.; Cseh, S. Assisted reproductive technologies in the reproductive management of small ruminants. Anim. Reprod. Sci. 2012, 130, 152-161.

127. Bertolini, M.; Bertolini, L.R. Advances in reproduc tive technologies in cattle: From artificial insemination to cloning. Rev. Med. Vet. Zoot. 2009, 56, 184-194.

128. Solti, L.; Crichton, E.G.; Loskutoff, N.M.; Cseh, S. Economical and ecological importance of indigenous livestock and the application of assisted reroduction to their preservation. Theriogenology 2000, 53, 149-162.

129. Barbieri, E.; kashyap, S.; Chung, P. Infertility and in vitro fertilization. In Priniciples of Gender Specific Medicine, 2nd ed.; Legato, M.J., Ed.; Academic Press: San Diego, CA, USA, 2010; pp. 381-398.

130. Tanbo, T.; Omland, A.; Dale, P.O.; Åbyholm, T. In vitro fertilization/embryo transfer in unexplained infertility and minimal peritoneal endometriosis. Acta Obstet. Gynecol. Scand. 1995, 74, 539-543.

131. Chandler, C.J.; Harris, C.P. Gamete intrafallopian transfer. Br. J. Hosp. Med. 1996, 55, 468-471.

132. Carnevale, E.M. Gamete intrafallopian transfer. Vet. Clin. N. Am. Equine Pract. 1996, 12, 47-60.

133. Jansen, R.P.S. Gamete intra-fallopian transfer. In Clinical in Vitro Fertilization; Springer London: London, UK, 1989; pp. 63-80.

134. Molloy, D.; Speirs, A.; Du Plessis, Y.; Gellert, S.; Bourne, H.; Johnston, W.I. Gamete intra-fallopian transfer. Med. J. Aust. 1985, 143, 428. 
135. Perone, N. Gamete intrafallopian transfer (GIFT): Historic perspective. J. Vitr. Fertil. Embryo Transf. 1991, 8, 1-4.

136. Asch, R.H.; Balmaceda, J.P.; Cittadini, E.; Casas, P.F.; Gomel, V.; Hohl, M.K.; Johnston, I.; Leeton, J.; Escudero, F.J.R.; Noss, U.; et al. Gamete intrafallopian transfer. Ann. N. Y. Acad. Sci. 1988, 541, 722-727.

137. Asch, R.H.; Balmaceda, J.P.; Ellsworth, L.R.; Wong, P.C. Gamete intra-fallopian transfer (GIFT): A new treatment for infertility. Int. J. Fertil. 1985, 30, 41-45.

138. Hummel, W.P.; Kettel, L.M. Assisted reproductive technology: The state of the ART. Ann. Med. 1997, 29, 207-214.

139. Devroey, P.; Staessen, C.; Camus, M.; de Grauwe, E.; Wisanto, A.; van Steirteghem, A.C. Zygote intrafallopian transfer as a successful treatment for unexplained infertility. Fertil. Steril. 1989, 52, 246-249.

140. Hamori, M.; Stuckensen, J.; Rumpf, D.; Kniewald, T.; Kniewald, A.; Marquez, M. Zygote intrafallopian transfer (ZIFT): Evaluation of 42 cases. Fertil. Steril. 1988, 50, 519-521.

141. Palermo, G.; Devroey, P.; Camus, M.; de Grauwe, E.; Khan, I.; Staessen, C.; Wisanto, A.; van Steirteghem, A.C. Zygote intra-Fallopian transfer as an alternative treatment for male infertility. Hum. Reprod. 1989, 4, 412-415.

142. Simpson, R. Assisted Reproductive Technology; NSW Parliamentary Library Research Service: Sydney, Australia, 1998; pp. 1-65.

143. Allen, V.M.; Wilson, R.D.; Cheung, A. Pregnancy outcomes after assisted reproductive technology. J. Obstet. Gynaecol. Can. 2006, 28, 220-250.

144. Wang, Y.A.C.G.; Sullivan, E.A. Assisted Reproductive Technology in Australia and New Zealand 2008; AIHW: Canberra, Australia, 2010.

145. Gianaroli, L.; Plachot, M.; van Kooij, R.; Al-Hasani, S.; Dawson, K.; DeVos, A.; Magli, M.C.; Mandelbaum, J.; Selva, J.; van Inzen, W. ESHRE guidelines for good practice in IVF laboratories. Committee of the special interest group on embryology of the european society of human reproduction and embryology. Hum. Reprod. 2000, 15, 2241-2246.

146. Engmann, L.; Maconochie, N.; Tan, S.L.; Bekir, J. Trends in the incidence of births and multiple births and the factors that determine the probability of multiple birth after IVF treatment. Hum. Reprod. 2001, 16, 2598-2605.

147. Pinborg, A. IVF/ICSI twin pregnancies: Risks and prevention. Hum. Reprod. Update 2005, 11, 575-593.

148. El-Toukhy, T.; Khalaf, Y.; Braude, P. IVF results: Optimize not maximize. Am. J. Obstet. Gynecol. 2006, 194, 322-331.

149. De Sutter, P.; van der Elst, J.; Coetsier, T.; Dhont, M. Single embryo transfer and multiple pregnancy rate reduction in IVF/ICSI: A 5-year appraisal. Reprod. BioMed. Online 2003, 6, 464-469.

150. Khalaf, Y.; El-Toukhy, T.; Coomarasamy, A.; Kamal, A.; Bolton, V.; Braude, P. Selective single blastocyst transfer reduces the multiple pregnancy rate and increases pregnancy rates: A pre- and postintervention study. BJOG 2008, 115, 385-390.

151. Tiitinen, A.; Unkila-Kallio, L.; Halttunen, M.; Hyden-Granskog, C. Impact of elective single embryo transfer on the twin pregnancy rate. Hum. Reprod. 2003, 18, 1449-1453. 
152. Menezes, J. Embryo culture systems. In Insights into Infertility Management; 2nd ed.; Jaypee Brothers Medical Publishers: New Delhi, India, 2012; pp. 188-198.

153. Gardner, D.K.; Lane, M. Embryo culture systems. In In Vitro Fertilization: A Practical Approach, Gardner, D.K., Ed.; Informa Healthcare USA, Inc.: New York, NY, USA, 2000; pp. 221-264.

154. Zander-Fox, D.; Lane, M. The Future of Human Embryo Culture Media-Or Have We Reached the Ceiling? In The Human Embryo, Yamada, S., Takakuwa, T., Eds.; InTech: Rijeka, Croatia, 2012; pp. 73-98.

155. Quinn, P. Review of media used in art laboratories. J. Androl. 2000, 21, 610-615.

156. Lane, M.; Gardner, D.K. Embryo culture medium: Which is the best? Best Pract. Res. Clin. Obstet. Gynaecol. 2007, 21, 83-100.

157. Quinn, P.; Kerin, J.F.; Warnes, G.M. Improved pregnancy rate in human in vitro fertilization with the use of a medium based on the composition of human tubal fluid. Fertil. Steril. 1985, 44, 493-498.

158. Gardner, D.K.; Lane, M. Culture and selection of viable blastocysts: A feasible proposition for human IVF? Hum. Reprod. Update 1997, 3, 367-382.

159. Gardner, D.K. Mammalian embryo culture in the absence of serum or somatic cell support. Cell Biol. Int. 1994, 18, 1163-1180.

160. Gupta, S. Media in ART. In Manual of Assisted Reproductive Technologies and Clinical Embryology, 2nd ed.; Jaypee Brothers Medical Publishers: New Delhi, India, 2012; pp.44-57.

161. Grace, K.S.; Sinclair, K.D. Assisted reproductive technology, epigenetics, and long-term health: A developmental time bomb still ticking. Semin. Reprod. Med. 2009, 27, 409-416.

162. Sinclair, K.D.; McEvoy, T.G.; Carolan, C.; Maxfield, E.K.; Maltin, C.A.; Young, L.E.; Wilmut, I.; Robinson, J.J.; Broadbent, P.J. Conceptus growth and development following in vitro culture of ovine embryos in media supplemented with bovine sera. Theriogenology 1998, 49, 218-218.

163. Sinclair, K.D.; McEvoy, T.G.; Maxfield, E.K.; Maltin, C.A.; Young, L.E.; Wilmut, I.; Broadbent, P.J.; Robinson, J.J. Aberrant fetal growth and development after in vitro culture of sheep zygotes. J. Reprod. Fertil. 1999, 116, 177-186.

164. Fernández-Gonzalez, R.; Ramirez, M.A.; Bilbao, A.; de Fonseca, F.R.; Gutiérrez-Adán, A. Suboptimal in vitro culture conditions: An epigenetic origin of long-term health effects. Mol. Reprod. Dev. 2007, 74, 1149-1156.

165. Thompson, J.G.; Gardner, D.K.; Pugh, P.A.; McMillan, W.H.; Tervit, H.R. Lamb birth weight is affected by culture system utilized during in vitro pre-elongation development of ovine embryos. Biol. Reprod. 1995, 53, 1385-1391.

166. Gardner, D.K.; Lane, M. Culture of viable human blastocysts in defined sequential serum-free media. Hum. Reprod. 1998, 13, 148-159; discussion 160.

167. Holst, N.; Bertheussen, K.; Forsdahl, F.; Hakonsen, M.B.; Hansen, L.J.; Nielsen, H.I. Optimization and simplification of culture conditions in human in vitro fertilization (IVF) and preembryo replacement by serum-free media. J. Vitr. Fertil. Embryo Transf. 1990, 7, 47-53.

168. Alwan, A. Global Status Report on Noncommunicable Diseases 2010; World Health Organization: Geneva, Switzerland, 2011.

169. World Health Organization. Global Health Observatory (GHO) Data. Available online: http://www.who.int/gho/ncd/mortality_morbidity/cvd/en/ (accessed on 16 November 2014). 
170. Stampfer, M.J.; Hu, F.B.; Manson, J.E.; Rimm, E.B.; Willett, W.C. Primary Prevention of Coronary Heart Disease in Women through Diet and Lifestyle. N. Engl. J. Med. 2000, 343, 16-22.

171. Mensah, G.A.; Mendis, S.; Greenland, K.; MacKay, J. The Atlas of Heart Disease and Stroke; World Health Organization: Geneva, Switzerland, 2004.

172. McMillen, I.C.; Robinson, J.S. Developmental origins of the metabolic syndrome: prediction, plasticity, and programming. Physiol. Rev. 2005, 85, 571-633.

173. Barker, D.J. The developmental origins of adult disease. Eur. J. Epidemiol. 2003, 18, 733-736.

174. De Boo, H.A.; Harding, J.E. The developmental origins of adult disease (Barker) hypothesis. Aust. N. Z. J. Obstet. Gynaecol. 2006, 46, 4-14.

175. Botting, K.J.; Wang, K.C.; Padhee, M.; McMillen, I.C.; Summers-Pearce, B.; Rattanatray, L.; Cutri, N.; Posterino, G.S.; Brooks, D.A.; Morrison, J.L. Early origins of heart disease: Low birth weight and determinants of cardiomyocyte endowment. Clin. Exp. Pharmacol. Physiol. 2012, 39, $814-823$.

176. Gluckman, P.D.; Hanson, M.A.; Buklijas, T.; Low, F.M.; Beedle, A.S. Epigenetic mechanisms that underpin metabolic and cardiovascular diseases. Nat. Rev. Endocrinol. 2009, 5, 401-408.

177. Chang, C.-P.; Bruneau, B.G. Epigenetics and cardiovascular development. Annu. Rev. Physiol. 2012, 74, 41-68.

178. Vallaster, M.; Vallaster, C.D.; Wu, S.M. Epigenetic mechanisms in cardiac development and disease. Acta Biochim. Biophys. Sin. 2012, 44, 92-102.

179. Ordovás, J.M.; Smith, C.E. Epigenetics and cardiovascular disease. Nat. Rev. Cardiol. 2010, 7 , 510-519.

180. Zak, R. Growth of the Heart in Health and Disease; Raven Press: New York, NY, USA, 1984.

181. Nag, A.C. Study of non-muscle cells of the adult mammalian heart: a fine structural analysis and distribution. Cytobios 1980, 28, 41-61.

182. Soonpaa, M.H.; Kim, K.K.; Pajak, L.; Franklin, M.; Field, L.J. Cardiomyocyte DNA synthesis and binucleation during murine development. Am. J. Physiol. 1996, 271, H2183-H2189.

183. Oparil, S.; Bishop, S.P.; Clubb, F.J. Myocardial cell hypertrophy or hyperplasia. Hypertension 1984, 6, III38-III43.

184. Schmid, G.; Pfitzer, P. Mitoses and binucleated cells in perinatal human hearts. Virchows Arch. $B$ 1985, 48, 59-67.

185. Burrell, J.H.; Boyn, A.M.; Kumarasamy, V.; Hsieh, A.; Head, S.I.; Lumbers, E.R. Growth and maturation of cardiac myocytes in fetal sheep in the second half of gestation. Anat. Rec. A Discov. Mol. Cell. Evol. Biol. 2003, 274, 952-961.

186. Ahuja, P.; Sdek, P.; MacLellan, W.R. Cardiac Myocyte Cell Cycle Control in Development, Disease, and Regeneration. Physiol. Rev. 2007, 87, 521-544.

187. Jonker, S.S.; Zhang, L.; Louey, S.; Giraud, G.D.; Thornburg, K.L.; Faber, J.J. Myocyte enlargement, differentiation, and proliferation kinetics in the fetal sheep heart. J. Appl. Physiol. 2007, 102, 1130-1142.

188. Woodcock, E.A.; Matkovich, S.J. Cardiomyocytes structure, function and associated pathologies. Int. J. Biochem. Cell Biol. 2005, 37, 1746-1751.

189. Walker, S.K.; Hartwich, K.; Robinson, J.S. Long-term effects on offspring of exposure of oocytes and embryos to chemical and physical agents. Hum. Reprod. Update 2000, 6, 564-577. 
190. Mollova, M.; Bersell, K.; Walsh, S.; Savla, J.; Das, L.T.; Park, S.-Y.; Silberstein, L.E.; dos Remedios, C.G.; Graham, D.; Colan, S.; et al. Cardiomyocyte proliferation contributes to heart growth in young humans. Proc. Natl. Acad. Sci. USA 2013, 110, 1446-1451.

191. Clubb, F.J., Jr.; Bishop, S.P. Formation of binucleated myocardial cells in the neonatal rat. An index for growth hypertrophy. Lab. Investig. 1984, 50, 571-577.

192. Porrello, E.R.; Mahmoud, A.I.; Simpson, E.; Hill, J.A.; Richardson, J.A.; Olson, E.N.; Sadek, H.A. Transient regenerative potential of the neonatal mouse heart. Science 2011, 331, 1078-1080.

193. Walsh, S.; Pontén, A.; Fleischmann, B.K.; Jovinge, S. Cardiomyocyte cell cycle control and growth estimation in vivo-An analysis based on cardiomyocyte nuclei. Cardiovasc. Res. 2010, 86, 365-373.

194. Li, F.; Wang, X.; Capasso, J.M.; Gerdes, A.M. Rapid transition of cardiac myocytes from hyperplasia to hypertrophy during postnatal development. J. Mol. Cell. Cardiol. 1996, 28, 1737-1746.

195. Roseboom, T.J.; van der Meulen, J.H.P.; Osmond, C.; Barker, D.J.P.; Ravelli, A.C.J.; Schroeder-Tanka, J.M.; van Montfrans, G.A.; Michels, R.P.J.; Bleker, O.P. Coronary heart disease after prenatal exposure to the Dutch famine, 1944-1945. Heart 2000, 84, 595-598.

196. Painter, R.C.; de Rooij, S.R.; Bossuyt, P.M.; Phillips, D.I.; Osmond, C.; Barker, D.J.; Bleker, O.P.; Roseboom, T.J. Blood pressure response to psychological stressors in adults after prenatal exposure to the Dutch famine. J. Hypertens. 2006, 24, 1771-1778.

197. Malik, S.; Cleves, M.A.; Honein, M.A.; Romitti, P.A.; Botto, L.D.; Yang, S.; Hobbs, C.A. National Birth Defects Prevention, S. Maternal Smoking and Congenital Heart Defects. Pediatrics 2008, 121, e810-e816.

198. Karatza, A.A.; Giannakopoulos, I.; Dassios, T.G.; Belavgenis, G.; Mantagos, S.P.; Varvarigou, A.A. Periconceptional tobacco smoking and Xisolated congenital heart defects in the neonatal period. Int. J. Cardiol. 2011, 148, 295-299.

199. Carmichael, S.L.; Shaw, G.M.; Yang, W.; Lammer, E.J. Maternal periconceptional alcohol consumption and risk for conotruncal heart defects. Birth Defects Res. Part A Clin. Mol. Teratol. 2003, 67, 875-878.

200. Van Driel, L.M.J.W.; Smedts, H.P.M.; Helbing, W.A.; Isaacs, A.; Lindemans, J.; Uitterlinden, A.G.; van Duijn, C.M.; de Vries, J.H.M.; Steegers, E.A.P.; Steegers-Theunissen, R.P.M. Eight-fold increased risk for congenital heart defects in children carrying the nicotinamide $\mathrm{N}$-methyltransferase polymorphism and exposed to medicines and low nicotinamide. Eur. Heart J. 2008, 29, 1424-1431.

201. Kwong, W.Y.; Wild, A.E.; Roberts, P.; Willis, A.C.; Fleming, T.P. Maternal undernutrition during the preimplantation period of rat development causes blastocyst abnormalities and programming of postnatal hypertension. Development 2000, 127, 4195-4202.

202. Watkins, A.J.; Wilkins, A.; Cunningham, C.; Perry, V.H.; Seet, M.J.; Osmond, C.; Eckert, J.J.; Torrens, C.; Cagampang, F.R.A.; Cleal, J.; et al. Low protein diet fed exclusively during mouse oocyte maturation leads to behavioural and cardiovascular abnormalities in offspring. J. Physiol. 2008, 586, 2231-2244. 
203. Watkins, A.J.; Ursell, E.; Panton, R.; Papenbrock, T.; Hollis, L.; Cunningham, C.; Wilkins, A.; Perry, V.H.; Sheth, B.; Kwong, W.Y.; et al. Adaptive responses by mouse early embryos to maternal diet protect fetal growth but predispose to adult onset disease. Biol. Reprod. 2008, 78, 299-306.

204. Edwards, L.J.; McMillen, I.C. Periconceptional nutrition programs development of the cardiovascular system in the fetal sheep. Am. J. Physiol. Regul. Integr. Comp. Physiol. 2002, 283, R669-R679.

205. Gardner, D.S.; Pearce, S.; Dandrea, J.; Walker, R.; Ramsay, M.M.; Stephenson, T.; Symonds, M.E. Peri-Implantation undernutrition programs blunted angiotensin ii evoked baroreflex responses in young adult sheep. Hypertension 2004, 43, 1290-1296.

206. Gopalakrishnan, G.S.; Gardner, D.S.; Rhind, S.M.; Rae, M.T.; Kyle, C.E.; Brooks, A.N.; Walker, R.M.; Ramsay, M.M.; Keisler, D.H.; Stephenson, T.; et al. Programming of adult cardiovascular function after early maternal undernutrition in sheep. Am. J. Physiol. Regul. Integr. Comp. Physiol. 2004, 287, R12-R20.

207. Cleal, J.K.; Poore, K.R.; Boullin, J.P.; Khan, O.; Chau, R.; Hambidge, O.; Torrens, C.; Newman, J.P.; Poston, L.; Noakes, D.E.; et al. Mismatched pre- and postnatal nutrition leads to cardiovascular dysfunction and altered renal function in adulthood. Proc. Natl. Acad. Sci. USA 2007, 104, 9529-9533.

208. Jaquiery, A.L.; Oliver, M.H.; Honeyfield-Ross, M.; Harding, J.E.; Bloomfield, F.H. Periconceptional undernutrition in sheep affects adult phenotype only in males. J. Nutr. Metab. 2012, $2012,7$.

209. Chen, M.; Norman, R.J.; Heilbronn, L.K. Does in vitro fertilisation increase type 2 diabetes and cardiovascular risk? Curr. Diabetes Rev. 2011, 7, 426-432.

210. Eisenberg, E. Long-term outcomes in children born after assisted conception. Semin. Reprod. Med. 2012, 30, 123-130.

211. Hart, R.; Norman, R.J. The longer-term health outcomes for children born as a result of IVF treatment: Part I-General health outcomes. Hum. Reprod. Update 2013, 19, 232-243.

212. Hart, R.; Norman, R.J. The longer-term health outcomes for children born as a result of IVF treatment. Part II-Mental health and development outcomes. Hum. Reprod. Update 2013, 19, 244-250.

213. Sinclair, K.D.; Young, L.E.; Wilmut, I.; McEvoy, T.G. In-utero overgrowth in ruminants following embryo culture: Lessons from mice and a warning to men. Hum. Reprod. 2000, 15, 68-86.

214. Rebecca, C.P.; Susanne, R.D.R.; Patrick, M.B.; Timothy, A.S.; Clive, O.; David, J.B.; Otto, P.B.; Tessa, J.R. Early onset of coronary artery disease after prenatal exposure to the Dutch famine. Am. J. Clin. Nutr. 2006, 84, 322-327.

215. Watkins, A.J.; Lucas, E.S.; Fleming, T.P. Impact of the periconceptional environment on the programming of adult disease. J. Dev. Orig. Health Dis. 2010, 1, 87-95.

216. Taitson, P.F.; Kwong, D.D.; Lima, G.C.D.A.; Coelho, L.S.; Bruce, W.D.; Bernardes, N.D.O. Incidence and anatomy of cardiac malformations in children conceived by assisted reproduction techniques-A review. JBRA Assist. Reprod. 2014, 18, 52-54.

217. Lancaster, P.A. Congenital malformations after in vitro fertilisation. Lancet 1987, 2, 1392-1393. 
218. Olson, C.K.; Keppler-Noreuil, K.M.; Romitti, P.A.; Budelier, W.T.; Ryan, G.; Sparks, A.E.; van Voorhis, B.J. In vitro fertilization is associated with an increase in major birth defects. Fertil. Steril. 2005, 84, 1308-1315.

219. Davies, M.J.; Moore, V.M.; Willson, K.J.; van Essen, P.; Priest, K.; Scott, H.; Haan, E.A.; Chan, A. Reproductive technologies and the risk of birth defects. N. Engl. J. Med. 2012, 366, 1803-1813.

220. Hansen, M.; Kurinczuk, J.J.; Bower, C.; Webb, S. The risk of major birth defects after intracytoplasmic sperm injection and in vitro fertilization. N. Engl. J. Med. 2002, 346, 725-730.

221. Anthony, S.; Buitendijk, S.E.; Dorrepaal, C.A.; Lindner, K.; Braat, D.D.; den Ouden, A.L. Congenital malformations in 4224 children conceived after IVF. Hum. Reprod. 2002, 17, 2089-2095.

222. Klemetti, R.; Gissler, M.; Sevon, T.; Koivurova, S.; Ritvanen, A.; Hemminki, E. Children born after assisted fertilization have an increased rate of major congenital anomalies. Fertil. Steril. 2005, 84, 1300-1307.

223. Wen, S.W.; Leader, A.; White, R.R.; Leveille, M.-C.; Wilkie, V.; Zhou, J.; Walker, M.C. A comprehensive assessment of outcomes in pregnancies conceived by in vitro fertilization/intracytoplasmic sperm injection. Eur. J. Obstet. Gynecol. Reprod. Biol. 2010, 150, $160-165$.

224. Mozafari Kermani, R.; Nedaeifard, L.; Nateghi, M.R.; Shahzadeh Fazeli, A.; Ahmadi, E.; Osia, M.A.; Jafarzadehpour, E.; Nouri, S. Congenital anomalies in infants conceived by assisted reproductive techniques. Arch. Iran. Med. 2012, 15, 228-231.

225. Koivurova, S.; Hartikainen, A.L.; Gissler, M.; Hemminki, E.; Sovio, U.; Jarvelin, M.R. Neonatal outcome and congenital malformations in children born after in vitro fertilization. Hum. Reprod. 2002, 17, 1391-1398.

226. Farhangniya, M.; Dortaj Rabori, E.; Mozafari Kermani, R.; Haghdoost, A.A.; Bahrampour, A.; Bagheri, P.; Lancestar, P.A.L.; Ashrafi, M.; Vosough Taqi Dizaj, A.; Gourabi, H.; et al. Comparison of congenital abnormalities of infants conceived by assisted reproductive techniques versus infants with natural conception in Tehran. Int. J. Fertil. Steril. 2013, 7, 217-224.

227. Reefhuis, J.; Honein, M.A.; Schieve, L.A.; Correa, A.; Hobbs, C.A.; Rasmussen, S.A. Assisted reproductive technology and major structural birth defects in the United States. Hum. Reprod. 2009, 24, 360-366.

228. Källén, B.; Finnström, O.; Nygren, K.G.; Olausson, P.O. In vitro fertilization (IVF) in Sweden: Risk for congenital malformations after different IVF methods. Birth Defects Res. Part A: Clin. Mol. Teratol. 2005, 73, 162-169.

229. Källén, B.; Finnström, O.; Lindam, A.; Nilsson, E.; Nygren, K.-G.; Otterblad, P.O. Congenital malformations in infants born after in vitro fertilization in Sweden. Birth Defects Res. Part A: Clin. Mol. Teratol. 2010, 88, 137-143.

230. Tararbit, K.; Houyel, L.; Bonnet, D.; de Vigan, C.; Lelong, N.; Goffinet, F.; Khoshnood, B. Risk of congenital heart defects associated with assisted reproductive technologies: A population-based evaluation. Eur. Heart J. 2011, 32, 500-508. 
231. Tararbit, K.; Lelong, N.; Thieulin, A.-C.; Houyel, L.; Bonnet, D.; Goffinet, F.; Khoshnood, B.; EPICARD Study Group. The risk for four specific congenital heart defects associated with assisted reproductive techniques: A population-based evaluation. Hum. Reprod. 2013, 28, 367-374.

232. Valenzuela-Alcaraz, B.; Crispi, F.; Bijnens, B.; Cruz-Lemini, M.; Creus, M.; Sitges, M.; Bartrons, J.; Civico, S.; Balasch, J.; Gratacos, E. Assisted reproductive technologies are associated with cardiovascular remodeling in utero that persists postnatally. Circulation 2013, 128, 1442-1450.

233. Ceelen, M.; van Weissenbruch, M.M.; Vermeiden, J.P.W.; van Leeuwen, F.E.; Delemarre-van de Waal, H.A. Cardiometabolic differences in children born after in vitro fertilization: follow-up study. J. Clin. Endocrinol. Metab. 2008, 93, 1682-1688.

234. Ceelen, M.; van Weissenbruch, M.M.; Prein, J.; Smit, J.J.; Vermeiden, J.P.; Spreeuwenberg, M.; van Leeuwen, F.E.; Delemarre-van de Waal, H.A. Growth during infancy and early childhood in relation to blood pressure and body fat measures at age 8-18 years of IVF children and spontaneously conceived controls born to subfertile parents. Hum. Reprod. 2009, 24, 2788-2795.

235. Sinaiko, A.R.; Donahue, R.P.; Jacobs, D.R.; Prineas, R.J. Relation of weight and rate of increase in weight during childhood and adolescence to body size, blood pressure, fasting insulin, and lipids in young adults: the minneapolis children's blood pressure study. Circulation 1999, 99, 1471-1476.

236. Law, C.M.; Shiell, A.W.; Newsome, C.A.; Syddall, H.E.; Shinebourne, E.A.; Fayers, P.M.; Martyn, C.N.; de Swiet, M. Fetal, infant, and childhood growth and adult blood pressure: a longitudinal study from birth to 22 years of age. Circulation 2002, 105, 1088-1092.

237. Sakka, S.D.; Loutradis, D.; Kanaka-Gantenbein, C.; Margeli, A.; Papastamataki, M.; Papassotiriou, I.; Chrousos, G.P. Absence of insulin resistance and low-grade inflammation despite early metabolic syndrome manifestations in children born after in vitro fertilization. Fertil. Steril. 2010, 94, 1693-1699.

238. Scherrer, U.; Rimoldi, S.F.; Rexhaj, E.; Stuber, T.; Duplain, H.; Garcin, S.; de Marchi, S.F.; Nicod, P.; Germond, M.; Allemann, Y.; et al. Systemic and pulmonary vascular dysfunction in children conceived by assisted reproductive technologies. Circulation 2012, 125, 1890-1896.

239. Charakida, M.; Deanfield, J.E.; Halcox, J.P. Childhood origins of arterial disease. Curr. Opin. Pediatr. 2007, 19, 538-545.

240. Urbina, E.M.; Williams, R.V.; Alpert, B.S.; Collins, R.T.; Daniels, S.R.; Hayman, L.; Jacobson, M.; Mahoney, L.; Mietus-Snyder, M.; Rocchini, A.; et al. Noninvasive assessment of subclinical atherosclerosis in children and adolescents: recommendations for standard assessment for clinical research: A scientific statement from the american heart association. Hypertension 2009, 54, 919-950.

241. Bonetti, P.O.; Lerman, L.O.; Lerman, A. Endothelial dysfunction a marker of atherosclerotic risk. Arterioscler. Thromb. Vasc. Biol. 2003, 23, 168-175.

242. Sitia, S.; Tomasoni, L.; Atzeni, F.; Ambrosio, G.; Cordiano, C.; Catapano, A.; Tramontana, S.; Perticone, F.; Naccarato, P.; Camici, P. From endothelial dysfunction to atherosclerosis. Autoimmun. Rev. 2010, 9, 830-834.

243. Van Popele, N.M.; Grobbee, D.E.; Bots, M.L.; Asmar, R.; Topouchian, J.; Reneman, R.S.; Hoeks, A.P.; van der Kuip, D.A.; Hofman, A.; Witteman, J.C. Association between arterial stiffness and atherosclerosis The Rotterdam Study. Stroke 2001, 32, 454-460. 
244. Bots, M.L.; Dijk, J.M.; Oren, A.; Grobbee, D.E. Carotid intima-media thickness, arterial stiffness and risk of cardiovascular disease: Current evidence. J. Hypertens. 2002, 20, 2317-2325.

245. Simons, P.C.; Algra, A.; Bots, M.L.; Grobbee, D.E.; van der Graaf, Y. Common carotid intima-media thickness and arterial stiffness: Indicators of cardiovascular risk in high-risk patients. The SMART Study (Second Manifestations of ARTerial disease). Circulation 1999, 100, 951-957.

246. Rooke, J.A.; McEvoy, T.G.; Ashworth, C.J.; Robinson, J.J.; Wilmut, I.; Young, L.E.; Sinclair, K.D. Ovine fetal development is more sensitive to perturbation by the presence of serum in embryo culture before rather than after compaction. Theriogenology 2007, 67, 639-647.

247. Powell, K.; Rooke, J.A.; McEvoy, T.G.; Ashworth, C.J.; Robinson, J.J.; Wilmut, I.; Young, L.E.; Sinclair, K.D. Zygote donor nitrogen metabolism and in vitro embryo culture perturbs in utero development and IGF2R expression in ovine fetal tissues. Theriogenology 2006, 66, 1901-1912.

248. Farin, P.W.; Farin, C.E. Transfer of bovine embryos produced in vivo or in vitro: Survival and fetal development. Biol. Reprod. 1995, 52, 676-682.

249. Van Wagtendonk-de Leeuw, A.M.; Mullaart, E.; de Roos, A.P.W.; Merton, J.S.; den Daas, J.H.G.; Kemp, B.; de Ruigh, L. Effects of different reproduction techniques: AI, moet or IVP, on health and welfare of bovine offspring. Theriogenology 2000, 53, 575-597.

250. McEvoy, T.G.; Sinclair, K.D.; Broadbent, P.J.; Goodhand, K.L.; Robinson, J.J. Post-natal growth and development of Simmental calves derived from in vivo or in vitro embryos. Reprod. Fertil. Dev. 1998, 10, 459-464.

251. Rexhaj, E.; Paoloni-Giacobino, A.; Rimoldi, S.F.; Fuster, D.G.; Anderegg, M.; Somm, E.; Bouillet, E.; Allemann, Y.; Sartori, C.; Scherrer, U. Mice generated by in vitro fertilization exhibit vascular dysfunction and shortened life span. J. Clin. Investig. 2013, 123, 5052-5060.

252. Young, L.E.; Sinclair, K.D.; Wilmut, I. Large offspring syndrome in cattle and sheep. Rev. Reprod. 1998, 3, 155-163.

253. Farin, P.W.; Piedrahita, J.A.; Farin, C.E. Errors in development of fetuses and placentas from in vitro-produced bovine embryos. Theriogenology 2006, 65, 178-191.

254. McEvoy, T.G.; Robinson, J.J.; Sinclair, K.D. Developmental consequences of embryo and cell manipulation in mice and farm animals. Reproduction 2001, 122, 507-518.

255. Wang, K.C.W.; Botting, K.J.; Padhee, M.; Zhang, S.; McMillen, I.C.; Suter, C.M.; Brooks, D.A.; Morrison, J.L. Early origins of heart disease: Low birth weight and the role of the insulin-like growth factor system in cardiac hypertrophy. Clin. Exp. Pharmacol. Physiol. 2012, 39, 958-964.

256. Wang, K.C.; Zhang, L.; McMillen, I.C.; Botting, K.J.; Duffield, J.A.; Zhang, S.; Suter, C.M.; Brooks, D.A.; Morrison, J.L. Fetal growth restriction and the programming of heart growth and cardiac insulin-like growth factor 2 expression in the lamb. J. Physiol. 2011, 589, 4709-4722.

257. Vinci, M.; Polvani, G.; Pesce, M. Epigenetic programming and risk: The birthplace of cardiovascular disease? Stem Cell Rev. Rep. 2013, 9, 241-253.

258. Heijmans, B.T.; Tobi, E.W.; Stein, A.D.; Putter, H.; Blauw, G.J.; Susser, E.S.; Slagboom, P.E.; Lumey, L.H. Persistent epigenetic differences associated with prenatal exposure to famine in humans. Proc. Natl. Acad. Sci. USA 2008, 105, 17046-17049. 
259. Tobi, E.W.; Lumey, L.H.; Talens, R.P.; Kremer, D.; Putter, H.; Stein, A.D.; Slagboom, P.E.; Heijmans, B.T. DNA methylation differences after exposure to prenatal famine are common and timing- and sex-specific. Hum. Mol. Genet. 2009, 18, 4046-4053.

260. Roseboom, T.; de Rooij, S.; Painter, R. The Dutch famine and its long-term consequences for adult health. Early Hum. Dev. 2006, 82, 485-491.

261. Sinclair, K.D.; Allegrucci, C.; Singh, R.; Gardner, D.S.; Sebastian, S.; Bispham, J.; Thurston, A.; Huntley, J.F.; Rees, W.D.; Maloney, C.A.; et al. DNA methylation, insulin resistance, and blood pressure in offspring determined by maternal periconceptional B vitamin and methionine status. Proc. Natl. Acad. Sci. USA 2007, 104, 19351-19356.

262. Celermajer, D.S. Manipulating nature: Might there be a cardiovascular price to pay for the miracle of assisted conception? Circulation 2012, 125, 1832-1834.

263. Horsthemke, B.; Ludwig, M. Assisted reproduction: The epigenetic perspective. Hum. Reprod. Update 2005, 11, 473-482.

264. DeBaun, M.R.; Niemitz, E.L.; Feinberg, A.P. Association of in vitro fertilization with Beckwith-Wiedemann syndrome and epigenetic alterations of LIT1 and H19. Am. J. Hum. Genet. 2003, 72, 156-160.

265. Gicquel, C.; Gaston, V.; Mandelbaum, J.; Siffroi, J.P.; Flahault, A.; le Bouc, Y. In vitro fertilization may increase the risk of Beckwith-Wiedemann syndrome related to the abnormal imprinting of the KCN1OT gene. Am. J. Hum. Genet. 2003, 72, 1338-1341.

266. Maher, E.R.; Brueton, L.A.; Bowdin, S.C.; Luharia, A.; Cooper, W.; Cole, T.R.; Macdonald, F.; Sampson, J.R.; Barratt, C.L.; Reik, W.; Hawkins, M.M. Beckwith-Wiedemann syndrome and assisted reproduction technology (ART). J. Med. Genet. 2003, 40, 62-64.

267. Halliday, J.; Oke, K.; Breheny, S.; Algar, E.; David, J.A. Beckwith-Wiedemann syndrome and IVF: A case-control study. Am. J. Hum. Genet. 2004, 75, 526-528.

268. Lim, D.; Bowdin, S.C.; Tee, L.; Kirby, G.A.; Blair, E.; Fryer, A.; Lam, W.; Oley, C.; Cole, T.; Brueton, L.A.; et al. Clinical and molecular genetic features of Beckwith-Wiedemann syndrome associated with assisted reproductive technologies. Hum. Reprod. 2009, 24, 741-747.

269. Rossignol, S.; Steunou, V.; Chalas, C.; Kerjean, A.; Rigolet, M.; Viegas-Pequignot, E.; Jouannet, P.; le Bouc, Y.; Gicquel, C. The epigenetic imprinting defect of patients with Beckwith-Wiedemann syndrome born after assisted reproductive technology is not restricted to the $11 \mathrm{p} 15$ region. J. Med. Genet. 2006, 43, 902-907.

270. Moll, A.C.; Imhof, S.M.; Cruysberg, J.R.; Schouten-van Meeteren, A.Y.; Boers, M.; van Leeuwen, F.E. Incidence of retinoblastoma in children born after in vitro fertilisation. Lancet 2003, 361, 309-310.

271. Mantikou, E.; Youssef, M.A.F.M.; van Wely, M.; van der Veen, F.; Al-Inany, H.G.; Repping, S.; Mastenbroek, S. Embryo culture media and IVF/ICSI success rates: A systematic review. Hum. Reprod. Update 2013, 19, 210-220.

272. Bromer, J.G.; Sakkas, D.; Seli, E. Metabolomic profiling of embryo culture media to predict IVF outcome. Expert Rev. Obstet. Gynecol. 2008, 3, 441-447.

273. Katari, S.; Turan, N.; Bibikova, M.; Erinle, O.; Chalian, R.; Foster, M.; Gaughan, J.P.; Coutifaris, C.; Sapienza, C. DNA methylation and gene expression differences in children conceived in vitro or in vivo. Hum. Mol. Genet. 2009, 18, 3769-3778. 
274. Lui, J.C.; Finkielstain, G.P.; Barnes, K.M.; Baron, J. An imprinted gene network that controls mammalian somatic growth is down-regulated during postnatal growth deceleration in multiple organs. Am. J. Physiol.Regul. Integr. Comp. Physiol. 2008, 295, R189-R196.

275. Olofsson, L.E.; Orho-Melander, M.; William-Olsson, L.; Sjoholm, K.; Sjostrom, L.; Groop, L.; Carlsson, B.; Carlsson, L.M.; Olsson, B. CCAAT/enhancer binding protein alpha (C/EBPalpha) in adipose tissue regulates genes in lipid and glucose metabolism and a genetic variation in $\mathrm{C} /$ EBPalpha is associated with serum levels of triglycerides. J. Clin. Endocrinol. Metab. 2008, 93, 4880-4886.

276. Mzhavia, N.; Yu, S.; Ikeda, S.; Chu, T.T.; Goldberg, I.; Dansky, H.M. Neuronatin: A new inflammation gene expressed on the aortic endothelium of diabetic mice. Diabetes 2008, 57, 2774-2783.

277. Wang, P.; Smit, E.; Brouwers, M.C.G.J.; Goossens, G.H.; van der Kallen, C.J.H.; van Greevenbroek, M.M.J.; Mariman, E.C.M. Plasma pigment epithelium-derived factor is positively associated with obesity in Caucasian subjects, in particular with the visceral fat depot. Eur. J. Endocrinol. 2008, 159, 713-718.

278. Linke, M.; May, A.; Reifenberg, K.; Haaf, T.; Zechner, U. The impact of ovarian stimulation on the expression of candidate reprogramming genes in mouse preimplantation embryos. Cytogenet. Genome Res. 2013, 139, 71-79.

279. Fauque, P. Ovulation induction and epigenetic anomalies. Fertil. Steril. 2013, 99, 616-623.

280. Geuns, E.; Hilven, P.; van Steirteghem, A.; Liebaers, I.; de Rycke, M. Methylation analysis of KvDMR1 in human oocytes. J. Med. Genet. 2007, 44, 144-147.

281. Sato, C.; Shimada, M.; Mori, T.; Kumasako, Y.; Otsu, E.; Watanabe, H.; Utsunomiya, T. Assessment of human oocyte developmental competence by cumulus cell morphology and circulating hormone profile. Reprod. BioMed. Online 2007, 14, 49-56.

282. Shi, W.; Haaf, T. Aberrant methylation patterns at the two-cell stage as an indicator of early developmental failure. Mol. Reprod. Dev. 2002, 63, 329-334.

283. Market-Velker, B.A.; Zhang, L.; Magri, L.S.; Bonvissuto, A.C.; Mann, M.R.W. Dual effects of superovulation: Loss of maternal and paternal imprinted methylation in a dose-dependent manner. Hum. Mol. Genet. 2010, 19, 36-51.

284. Laprise, S.L. Implications of epigenetics and genomic imprinting in assisted reproductive technologies. Mol. Reprod. Dev. 2009, 76, 1006-1018.

285. Paoloni-Giacobino, A.; Chaillet, J.R. Genomic imprinting and assisted reproduction. Reprod. Health 2004, 1, 6-12.

286. Li, T.; Vu, T.H.; Ulaner, G.A.; Littman, E.; Ling, J.-Q.; Chen, H.-L.; Hu, J.-F.; Behr, B.; Giudice, L.; Hoffman, A.R. IVF results in de novo DNA methylation and histone methylation at an Igf2-H19 imprinting epigenetic switch. Mol. Hum. Reprod. 2005, 11, 631-640.

287. Doherty, A.S.; Mann, M.R.; Tremblay, K.D.; Bartolomei, M.S.; Schultz, R.M. Differential effects of culture on imprinted H19 expression in the preimplantation mouse embryo. Biol. Reprod. 2000, 62, 1526-1535.

288. Mann, M.R.; Lee, S.S.; Doherty, A.S.; Verona, R.I.; Nolen, L.D.; Schultz, R.M.; Bartolomei, M.S. Selective loss of imprinting in the placenta following preimplantation development in culture. Development 2004, 131, 3727-3735. 
289. Wolff, G.L.; Kodell, R.L.; Moore, S.R.; Cooney, C.A. Maternal epigenetics and methyl supplements affect agouti gene expression in Avy/a mice. FASEB J. 1998, 12, 949-957.

290. Armant, D.R. Blastocysts don't go it alone. Extrinsic signals fine-tune the intrinsic developmental program of trophoblast cells. Dev. Biol. 2005, 280, 260-280.

291. Saito, S. Cytokine cross-talk between mother and the embryo/placenta. J. Reprod. Immunol. 2001, 52, 15-33.

292. Burke, A.C.; Nelson, C.E.; Morgan, B.A.; Tabin, C. Hox genes and the evolution of vertebrate axial morphology. Development 1995, 121, 333-346.

293. Boerjan, M.L.; den Daas, J.H.G.; Dieleman, S.J. Embryonic origins of health: Long term effects of IVF in human and livestock. Theriogenology 2000, 53, 537-547.

294. Van Soom, A.; Boerjan, M.L.; Bols, P.E.; Vanroose, G.; Lein, A.; Coryn, M.; de Kruif, A. Timing of compaction and inner cell allocation in bovine embryos produced in vivo after superovulation. Biol. Reprod. 1997, 57, 1041-1049.

295. Van Soom, A.; Boerjan, M.; Ysebaert, M.-T.; de Kruif, A. Cell allocation to the inner cell mass and the trophectoderm in bovine embryos cultured in two different media. Mol. Reprod. Dev. 1996, $45,171-182$.

296. Olson, E.N.; Schneider, M.D. Sizing up the heart: Development redux in disease. Genes Dev. 2003, 17, 1937-1956.

297. Van Montfoort, A.P.; Hanssen, L.L.; de Sutter, P.; Viville, S.; Geraedts, J.P.; de Boer, P. Assisted reproduction treatment and epigenetic inheritance. Hum. Reprod. Update 2012, 18, 171-197.

(C) 2015 by the authors; licensee MDPI, Basel, Switzerland. This article is an open access article distributed under the terms and conditions of the Creative Commons Attribution license (http://creativecommons.org/licenses/by/4.0/). 